\title{
Estruturação organizacional- institucional dos municípios na governança da gestão de risco de desastres em bacias hidrográficas
}

\author{
Organizational-institutional structuring of municipalities \\ in the governance of disaster risk management in \\ watershed
}

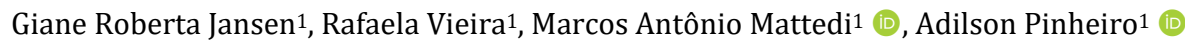

${ }^{1}$ Fundação Universidade Regional de Blumenau, Blumenau, SC, Brasil. E-mails: giane.jansen@gmail.com, arquitetura.rafaela@gmail.com, mattediblu@gmail.com,pinheiro@furb.br

\begin{abstract}
Como citar: Jansen, G.R., Vieira, R., Mattedi, M.A., \& Pinheiro A. (2021). Estruturação organizacional-institucional dos municípios na governança da gestão de risco de desastres em bacias hidrográficas. Revista de Gestão de Água da América Latina, 18 , e1. https://doi.org/10.21168/rega.v18e1
\end{abstract}

RESUMO: 0 número crescente de registros de desastres deflagrados pela água evidencia a necessária estruturação da gestão de riscos de desastres, em processo de governança. 0 nível territorial regional torna-se estratégico no tratamento das fragilidades econômicas e técnico-administrativas dos municípios brasileiros. Assim, este trabalho objetivou desenvolver uma metodologia para analisar a estruturação organizacional-institucional a fim de contribuir para o processo de tomada de decisão na governança da gestão de riscos de desastres nos níveis territoriais municipal e regional, como as Associações de Municípios e Comitês de Bacia Hidrográfica. O Índice de Estruturação Organizacional-Institucional (IEOI) desenvolvido teve base em indicadores de recursos humanos, organizacional, operacional, infraestrutura e de recursos financeiros. A pesquisa teve abordagem quali-quantitativa, explicativa, com análise documental e aplicação de questionários. 0 estudo de caso foi a região da bacia hidrográfica do Rio Itajaí (BHRI), que possui três associações de municípios. Observam-se: a) baixos valores de IEOI; b) a correlação destes valores com a população estimada por município; e c) a constatação do processo de vulnerabilização à riscos de desastres na BHRI. A aplicação do IEOI propiciou uma visão de diferentes níveis territoriais, contribuindo para tomada de decisão em processos de gestão integrada.

Palavras-chave: Gestão de Risco de Desastre; Avaliação da Governança; Índice de Estruturação OrganizacionalInstitucional.

ABSTRACT: The growing number of disaster records triggered by water highlights the necessary structuring of disaster risk management, in the governance process. The regional territorial level becomes strategic in dealing with the economic and technical-administrative weaknesses of Brazilian municipalities. Thus, this work aimed to develop a methodology to analyze the organizational-institutional structuring in order to contribute to the decision-making process in the governance of disaster risk management at the municipal and regional territorial levels, such as Municipal Associations and Basin Committees Hydrographic. The Organizational-Institutional Structuring Index (IEOI) developed was based on indicators of human, organizational, operational, infrastructure and financial resources. The research had a qualitative-quantitative, explanatory approach, with documentary analysis and application of questionnaires. The case study was the region of the Itajaí River watershed (BHRI), which has three associations of municipalities. We observe: a) low values of IEOI; b) the correlation of these values with the estimated population by municipality; and c) the verification of the vulnerability to disaster risk at BHRI. The application of IEOI provided a view of different territorial levels, contributing to decision making in integrated management processes.

Keywords: Disaster Risk Management; Governance Assessment; Organizational-Institutional Structuring Index.

Recebido: Dezembro 24, 2020. Revisado: Fevereiro 01, 2021. Aceito: Fevereiro 09, 2021. 


\section{INTRODUÇÃO}

Os impactos dos desastres relacionados ao clima compreendem um fenômeno que vem se intensificando globalmente nas últimas décadas, com o aumento crescente no número de registros e perdas constitui um dos principais desafios ao desenvolvimento socioeconômico de muitas regiões. Segundo Wallemacq et al. (2018), no Emergency Events Database (EM-DAT), somente no período de 1998-2017 foram registrados US \$2,908 bilhões em perdas econômicas mundiais, causados por enchentes, tempestades, terremotos, temperaturas extremas, deslizamentos, secas, incêndios, atividades vulcânicas e movimentos de massa (seca). Os dados representam somente uma fração do total, por conta não somente das subnotificações, mas também das perdas indiretas que, frequentemente, não costumam ser contabilizadas (Guha-Sapir \& Santos, 2013).

o Brasil está entre os dez países com o maior número absoluto de atingidos nos últimos 20 anos, com 51 milhões de brasileiros impactados pelos desastres neste período, com o número de registros de ocorrências de desastres quase duplicando na última década (Nações Unidas, 2015a). Neste sentido, a perda brasileira acumulada com desastres naturais no período de 1995 a 2014 atingiu cerca de 182,8 bilhões de reais (Banco Mundial, 2018), somente no que diz respeito às perdas diretas. Em 2019, o Brasil ficou na terceira posição das Américas com 295.000 novos deslocamentos de população, sendo a maioria desencadeados por inundações e deslizamentos de terra (Internal Displacement Monitoring Center's, 2020).

Embora as perdas e danos geradas por desastres sejam expressivas, o processo histórico de construção conceitual do risco ganha força apenas na segunda metade do século XX. No início da década de 1950, o risco tinha abordagens baseadas no perigo, na ameaça. No final da década de 1970 - início da década de 1980, passa-se a compreender que o risco possui uma dimensão social, a 'Gestão de Desastres'; para que nos anos 2000, se compreendesse que o risco é uma construção social e, não apenas uma de suas dimensões (Nações Unidas, 2019). Este processo conceitual do risco passa a receber maior repercussão mundial à partir da década 1990, com marcos e programas internacionais vinculados à Organização das Nações Unidas (ONU), através do Escritório das Nações Unidas para a Redução do Risco de Desastres (UNISDR): a instituição de 1990 como a Década Internacional para Redução de Riscos Naturais (IDNDR); o Marco de Yokohama (Nações Unidas, 1994) como primeiro plano internacional de estratégias e ações para um mundo mais seguro; o Marco de Hyogo (Nações Unidas, 2005) para o aumento da resiliência das nações e comunidades frente ao risco.

Em 2015, o Marco de Ação de Sendai avança com a instituição de metas e princípios para a redução de riscos de desastres para o desenvolvimento sustentável, estabelecendo quatro prioridades de ação: 1) compreender o risco de desastres; 2) fortalecer a governança do risco de desastres; 3 ) investir na redução do risco de desastres para a resiliência; e 4) aumentar a preparação para desastres para uma resposta eficaz e para 'reconstruir melhor' em recuperação, reabilitação e reconstrução (Nações Unidas, 2015b). No mesmo ano, ocorre um grande alinhamento em acordos, marcos e agendas internacionais que evidenciam questões subjacentes ao risco (por exemplo, pobreza, rapidez e informalidade urbanização, problemas crônicos de saúde, entre outras): Nova Agenda Urbana (NUA) - Habitat III, o Acordo de Paris - United Nations Framework Convention on Climate Change (UNFCCC); Agenda 2030 para o Desenvolvimento Sustentável - Objetivos de Desenvolvimento Sustentável (ODS) (Nações Unidas, 2019). Cabe destacar também que o aprimoramento conceitual associado à gestão de riscos de desastres (GRD) que já vinha ocorrendo se substancia, sendo incorporados de forma enfática os termos 'risco sistêmico' e 'sistemas adaptativos complexos' (International Risk Governance Council, 2018) e 'sistemas adaptativos e integrativos de gestão de risco' (Ishiwatari, 2019) - em uma visão sistêmica.

Desdobramentos destes esforços internacionais e a ocorrências de desastres de grandes proporções no Brasil (destaque para a região do Vale do Itajaí em 2008 e para a região serrana do Rio de Janeiro em 2011) redefiniram as estratégias de concepção e confrontação dos desastres naturais. A incorporação da GRD se materializou na Política Nacional de Proteção e Defesa Civil (PNPDEC), Lei № 12.608, de 10 de abril de 2012 (Brasil, 2012), que prevê a atuação nos processos de geração do conhecimento, prevenção, mitigação, preparação, resposta e recuperação. A PNPDEC institui a bacia hidrográfica como unidade de planejamento, além de prever sua integração com as políticas de ordenamento territorial, desenvolvimento urbano, saúde, meio ambiente, mudanças climáticas, gestão de recursos hídricos, geologia, infraestrutura, educação, ciência e tecnologia e às demais políticas setoriais. Como a água é o elemento deflagrador de inundações e deslizamentos de terra, a PNPDEC se alinha com a Política Nacional de Recursos Hídricos (PNRH), Lei № 9.433, 08 de janeiro de 1997 (Brasil, 1997). 
Dada a importância da integração de políticas públicas, estudos de Dulac \& Kobiyama (2017) sobre as políticas brasileiras de recursos hídricos, de saneamento e gestão de risco de desastres revelam que embora essas políticas possuam objetivos comuns, suas ações têm sido realizadas de modo fragmentado entre os setores, sem estratégias integradas, ou seja, sem gestão integrada.

Neste contexto emerge a questão da gestão no território e seus diferentes níveis territoriais: 0 internacional, o nacional, o estadual, o regional - de arranjos como as Associações de Município e Comitês de bacia hidrográfica, e o local - do município, e o comunitário. A interdependência e a colaboração horizontal e vertical entre esses níveis territoriais são necessários aos processos de governança e gestão integrada. Este processo torna-se viável à medida que existe estruturação organizacional e institucional para a sua implementação que possibilite a participação dos atores na rede de gestão, de diferentes níveis territoriais e diferentes políticas de desenvolvimento.

A PNPDEC e a PNRH evidenciam o nível territorial regional quando tomam a bacia hidrográfica como unidade de planejamento. Entre o nível territorial regional e o local se observa uma lacuna para gestão integrada, bem como uma oportunidade para estas políticas. Considerando que é nos municípios que as políticas públicas se materializam (Nogueira et al., 2014), também é no nível local que as ações podem ser aplicadas de forma integrada. 0 necessário protagonismo do nível territorial local deve ser considerado juntamente ao planejamento estratégico de nível territorial regional destas políticas.

A gestão de risco de desastres abrange os momentos pré e pós-desastres, em um processo complexo, explícito e presente no desenho de políticas, estratégias e instrumentos de desenvolvimento, em diferentes escalas territoriais, com a integração, coordenação e diálogo com a sociedade civil e agentes sociais (Narváez et al., 2009). Essa complexidade já inicia no conceito sistêmico de risco (International Risk Governance Council, 2018), que é formado socialmente (Beck, 2015): a população pode estar mais ou menos vulnerável à determinados riscos de desastres.

0 conceito de vulnerabilidade já passou por muita discussão na literatura. Wisner et al. (2004) entende a vulnerabilidade como um modelo de progressão que produzem resultados danosos à determinada população e ao ambiente do entorno. A vulnerabilidade inclui quer elementos de exposição ao risco, quer de propensão, como as circunstâncias que aumentam ou reduzem a capacidade da população, da infraestrutura ou dos sistemas físicos para responder a e recuperar de ameaças ambientais (Cutter, 2011).

Assim como a abordagem sistêmica da gestão de recursos hídricos, a governança de risco de desastres considera importante a forma como as informações relevantes sobre os riscos são coletadas, analisadas, compreendidas e comunicadas, e como as decisões de gestão são tomadas e divulgadas. A governança de riscos é compreendida como um processo de explorar as características da exposição e da vulnerabilidade que compõem o risco e identificar as oportunidades de ação (International Risk Governance Council, 2017). Também deve considerar a capacidade organizacional em diversos níveis territoriais (local, estadual ou nacional), a política e regulação de riscos baseados em aspectos culturais, as dimensões sociais das mudanças climáticas e a cultura do risco, a rede de atores ou indivíduos deve ser efetivamente representativa e utilizando a comunicação de riscos como estratégia de orientação e empoderamento da sociedade diante dos riscos em que estão ou são submetidas (Iwama et al., 2016). Estudos de Djalante e Lassa (2019) mostram que já houve progresso no planejamento e implementação de gestão de risco de desastres no âmbito internacional, regional e nacional, principalmente em termos de formação de organizações e redes para a redução de riscos de desastres; mas destacam a necessidade de aumentar a capacidade dos atores locais, fornecendo mais recursos, dados e capacidade para a tomada de decisões.

Mizutori (2019) mostra que melhores dados econômicos, complementados por dados socioecológicos, devem: a) conduzir o planejamento nos níveis nacional e local para garantir a redução de riscos; b) incluir a adaptação às mudanças climáticas; e c) fornecer as orientações claras sobre como evitar a criação de novos riscos. Um sistema robusto de governança municipal, em que as funções e as responsabilidades de diferentes níveis de governança estão claramente delineadas é necessário para que a resiliência das cidades seja construída (Das \& Majumdar, 2019). Um sistema de governança municipal requer estruturação organizacional-institucional para torna-se viável e ser capaz de relacionar-se com diferentes escalas territoriais.

A maioria dos municípios brasileiros é de pequeno porte e apresenta fragilidades econômicas e técnico-administrativas e sua estruturação organizacional-institucional é reflexo desse contexto. Nogueira et al. (2014) destacam a importância de investir na organização regional da gestão de risco de desastres, como forma de avançar no planejamento sinérgico das capacidades dos municípios. 
Neste contexto, são representativas as contribuições das Associações de Municípios no planejamento de regiões.

Para que a governança e a gestão de risco de desastre sejam fortalecidas, é necessário analisar e compreender suas dimensões. Narváez et al. (2009) destacam que a estruturação organizacionalinstitucional é princípio básico para a gestão de risco de desastres. Garcias et al. (2019) também consideram que a "utilização de instrumentos que avaliem a gestão de riscos e desastres dos municípios é essencial para a promoção de medidas que auxiliem os gestores a tornarem suas cidades mais resilientes" (Garcias et al., 2019, p. 1).

Internacionalmente, metodologias de mensuração de risco e vulnerabilidade social a desastres naturais tem recorrente enfoque na comparação entre países (BRAGA et al., 2006): o Disaster Risk Reduction Index (DRI), do Programa das Nações Unidas para o Desenvolvimento (2014); o Natural Disaster Hotspots: a Global Risk Analysis (Hotspots), do Banco Mundial, Universidade Columbia NY e ProVention Consortium (DILLEY et al., 2005); e o New Indicators of vulnerability and adaptative capacity, do Tyndall Centre (ADGER et al., 2004). Em escala nacional, Cutter (2011) discute modelos, métodos e indicadores para desenvolver o Índice de Vulnerabilidade Social à riscos ambientais nos Estados Unidos da América; no Brasil, o Ministério do Meio Ambiente, Ministério da Integração Nacional, WWF-Brasil lançam o Índice de vulnerabilidade aos desastres naturais relacionados às secas no contexto da mudança do clima (Brasil, 2017). Freitas (2017) realiza análise dos órgãos de proteção e defesa civil do Estado do Ceará, mas sem estabelecer um índice.

o Disaster Resilience Scorecard for Cities (DRSC) foi desenvolvido pelas Nações Unidas como uma ferramenta de autoavaliação da resiliência à desastres em nível territorial local, para apoiar os relatórios e implementação do Quadro de Ação de Sendai para Redução do Risco de Catástrofes: Baseado nos Dez Princípios para Construir Cidades Resilientes de 2015-2030 (Nações Unidas, 2017). O DRSC contempla dez princípios, dos quais desdobram dez dimensões de análise. Destacamos a dimensão 1 - "Implementar uma estrutura organizacional e identificar os processos necessários para compreender e atuar na redução do risco de catástrofes", em que são avaliados apenas três indicadores: a) a existência de plano de redução de riscos de desastres alinhado com o Marco de Sendai; b) a existência de um mecanismo multi-agência/setorial para redução de riscos; e c) integração com outras políticas/planos setoriais. A visão compartilhada pelos autores é de que a estruturação organizacional-institucional dos municípios para a gestão de risco de desastres vai bem além destes indicadores. Também acerca da integração da gestão de risco de desastres com as demais políticas urbanas, considera-se que se trata de uma avaliação muito mais robusta - à título do que Dulac \& Kobiyama (2017) desenvolveram - que as alternativas disponibilizadas nessa avaliação do DRSC.

Paralelamente ao desenvolvimento desse estudo, Garcias et al. (2019) desenvolveram o Indicador de Preparação a Desastres para Cidades (IPDC), também como uma forma de aprimorar o Disaster Resilience Scorecard for Cities (DRSC). 0 estudo foi aplicado apenas à dois municípios, tendo foco na análise comparativa entre eles: enfoque em nível territorial local.

O desenvolvimento de um Índice de Estruturação Organizacional-Institucional (IEOI) pretende proporcionar uma compreensão facilitada da realidade dos municípios para a governança da GRD, podendo ser visualizado enquanto índice geral ou por grupo de indicadores, o que facilita verificar grupos mais fragilizados, sem que fiquem mascarados no número final do índice. Comparativamente à outros índices de gestão de risco apresentados, o IEOI além de se apresentar como base de dados para a tomada de decisões para a governança da gestão de risco de desastres nos níveis local (municípios); também explora a visão conjunta dos dados em nível territorial regional, já que as Associações de Municípios (AMs) e Comitês de Bacia Hidrográfica podem ter papel crucial na implementação e potencialização de ações conjuntas com municípios. 0 estudo também analisa correlações do IEOI com características da região, além de gerar uma análise de Matriz de Vulnerabilidade Local, indicando quais os municípios devem ter ação prioritária.

Nesse sentido, a região da bacia hidrográfica do Rio Itajaí (BHRI), em Santa Catarina, é escolhida como estudo de caso por ser bacia altamente vulnerável a desastres e com registros históricos de desastres deflagrados pela água: inundações (Frank \& Pinheiro, 2003) e deslizamentos (Mattedi et al., 2018), bem como as perdas e danos associados (Tachini, 2010). A BHRI é referência nacional em relação à gestão de risco de desastres com a atuação da Defesa Civil nas grandes enchentes de 1983 e 1984 e a criação do primeiro sistema de alerta nacional, o Centro de Operações do Sistema de Alerta da Bacia do Itajaí (CEOPS), em parceria com a Universidade Regional de Blumenau. 0 capital social regional também pode ser notado com o pioneirismo na criação do Comitê do Itajaí em 1996 (oficializado em 1997 pelo Estado e instalado em 1998) antes da criação da PNRH pela Lei no 9.433, 
de 08 de janeiro de 1997 (Frank \& Bohn, 2018); e pelas Associações de Municípios da BHRI que permanecem operantes e funcionais desde a década de 1960 (Siebert, 2010).

\section{MATERIAL E MÉTODOS}

Conforme a Nações Unidas (2015, 2019) e PreventionWeb (2019) a natureza sistêmica da temática estudada requer a escolha de técnicas, métodos e instrumentos de pesquisa que não a reduzam. Por isto, a concepção e o desenvolvimento metodológico da pesquisa quali-quantitativa (mista) (Creswel, 2010), estruturada nas etapas de levantamento, sistematização, análise e síntese (Figura 1).

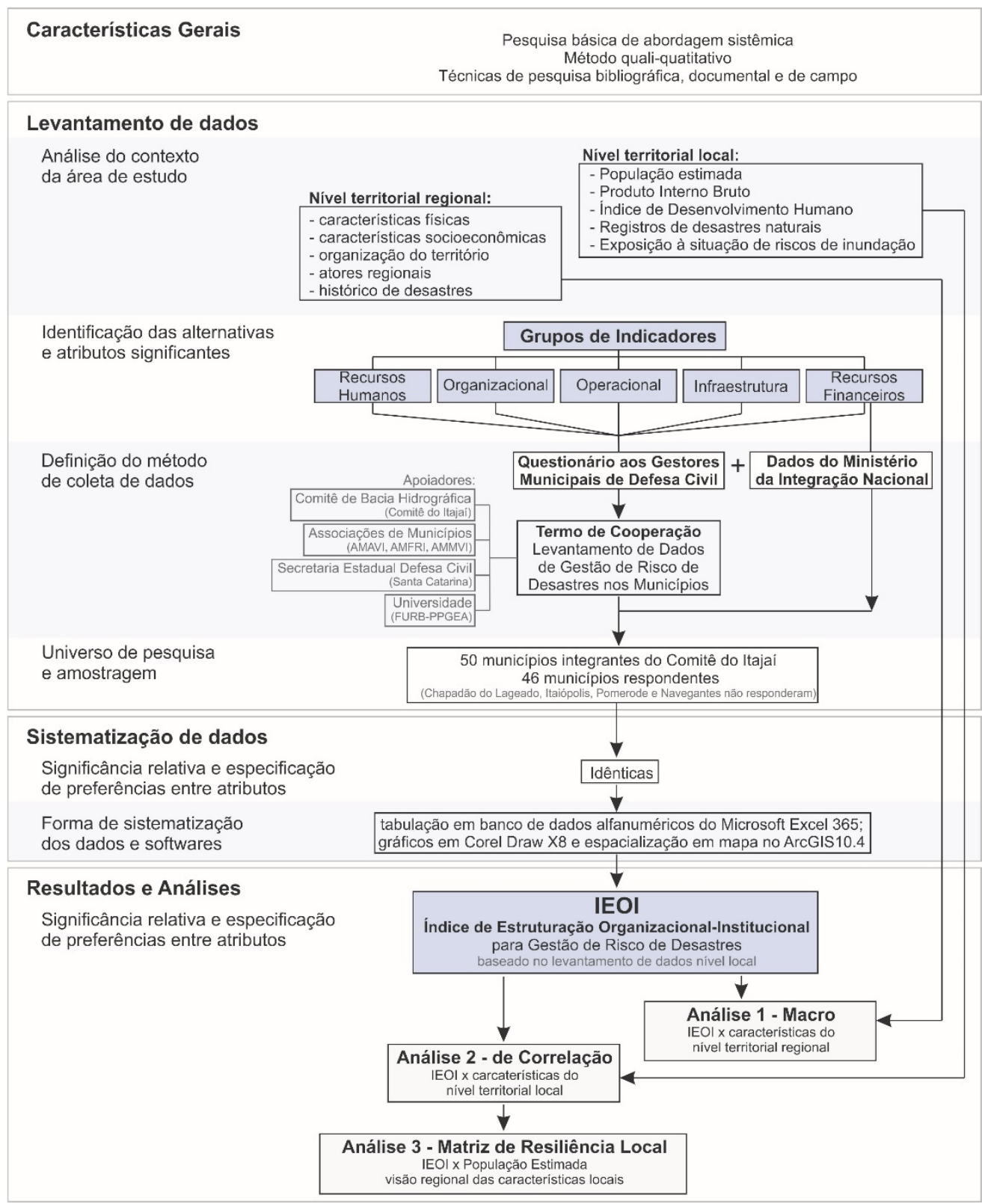

Figura 1 - Características da Pesquisa e fluxo metodológico adotado no estudo.

O estudo é baseado na utilização de técnicas de pesquisa bibliográfica, documental e de campo com o uso de questionários, com a técnica de análise de conteúdo e a estatística descritiva univariada. A pesquisa se estruturou em 1) levantamento de dados -1.1) análise do contexto da área de estudo em nível territorial local e regional, 1.2) identificação das alternativas e atributos significantes, com a definição dos indicadores, subindicadores e seus agrupamentos; 1.3) definição do método de coleta de dados municipais por Termo de Cooperação interinstitucional e dados do então Ministério da 
Integração Nacional, hoje de Desenvolvimento Regional; 2) sistematização de dados - 2.1) considerando idêntica a significância relativa e especificação de preferencias entre atributos; 2.2) forma de sistematização de dados com a tabulação de dados em software Microsoft Excel 365, elaboração de gráficos no software Corel Draw X8 e espacializações em mapa no software ArcGIS 10.4; e 3) resultados e análises, em que, com base no resultado principal, 3.1) o IEOI, foram desenvolvidas as 3.2) Análises Macro, 3.3) de Correlação e 3.4) Matriz de Resiliência Local. As características e o fluxo metodológico da pesquisa são apresentados na Figura 1.

Os dados utilizados para o estudo provêm do Levantamento de Dados GRD na região da BHRI, realizado de março a outubro de 2018, por meio de Termo de Cooperação entre a Universidade Regional de Blumenau (FURB), Associação do Municípios do Alto Vale do Itajaí (AMAVI), Associação dos Municípios do Médio Vale do Itajaí (AMMVI), Associação dos Municípios da Foz do Itajaí (AMFRI), o Comitê do Itajaí e a Secretaria de Estado da Defesa Civil. Também foram utilizados como indicadores dados disponibilizados pelo então Ministério da Integração Nacional.

0 recorte territorial do levantamento de dados GRD na região da BHRI - e que representa a BHRI nesse estudo - são os 50 municípios abrangidos pelo Comitê do Itajaí como universo da pesquisa. 0 levantamento de dados foi realizado em 2018 por meio de questionário direcionado ao Gestor Municipal de Defesa Civil. Quatro municípios não participaram do levantamento da GRD na região da BHRI: Chapadão do Lageado, Itaiópolis, Navegantes e Pomerode.

A análise dos dados resultou no Índice de Estruturação Organizacional-Institucional (IEOI) da bacia hidrográfica do Rio Itajaí e seus municípios. Com os IEOIs municipais encontrados foram realizadas três análises: 1) Análise Macro - considerando características do contexto regional e gerando o IEOI da BHRI e das Associações de Municípios; 2) Análise de Correlação - buscando encontrar variáveis explicativas para o IEOI com dados municipais (especificados no item Área de Estudo); e 3) Análise da Matriz de Resiliência Local - avalia os cenários dos municípios a partir da relação entre sua capacidade de estruturação organizacional-institucional e a vulnerabilidade à riscos de desastres.

\section{Índice de Estruturação Organizacional-Institucional (IEOI)}

Para composição do IEOI foram elencados diferentes Grupos de Indicadores (GI): de Recursos Humanos ( 2 indicadores com 11 subindicadores), Organizacional (6 indicadores), Operacional (11 indicadores), Infraestrutura (17 indicadores) e de Recursos Financeiros (4 indicadores), apresentados na Tabela 1. A seleção dos 40 indicadores (e 11 subindicadores) considera os conceitos de governança e gestão de risco de desastres (Brasil, 2012, 2017; International Risk Governance Council, 2017; Narváez et al., 2009; Nações Unidas, 2015) e das recomendações do Ministério da Integração Nacional (Brasil, 2017). Os GIs têm ponderação idêntica na composição do IEOI: cada um dos cinco GIs representam $20 \%$ na composição do IEOI-GRD, com pontuação máxima igual a 1,0. 0 valor final do IEOI de cada município é composto por um simples somatório da pontuação encontrada em cada indicador. Na composição do índice, qualquer indicador que não foi respondido ou obteve resposta que não atende a questão, não teve valor atribuído (zero). Os GIs e IEOIs da BHRI e das AMs também consideram as médias aritméticas dos municípios.

Sobre os GIs, destacamos características do GI de Recursos Humanos e do GI de Recursos Financeiros. 0 GI Recursos Humanos tem seus indicadores compostos por subindicadores de igual ponderação entre si, além de apresentar algumas peculiaridades em sua composição e nos critérios utilizados para sua aferição, explicitados na Tabela 2. Evidencia-se que o nível de instrução do gestor e da equipe, e a quantidade e tipo de vínculo dos colaboradores apresentam uma classificação gradual e cumulativa à medida que contribuem ao processo. 0 GI Recursos Financeiros teve enfoque associado à capacidade de recebê-los, e não à quantidade de vezes ou os valores recebidos. Salienta-se que no Brasil, os recursos financeiros para GRD têm grande associação à cultura da gestão compensatória, baseada nos processos de preparação, de resposta e, principalmente, de recuperação; com foco ainda na gestão do desastre e não do risco. Também os repasses financeiros podem estar associados à manutenção de uma rede hierárquica (vertical, com repasses federais aos Estados e municípios), que inibem e/ou coíbem a transversalidade (relações horizontais) desejada nas redes multinível do macroprocesso de governança de riscos de desastres. A capacidade de receber recursos financeiros considerou em três aspectos: a atualização do cadastro na plataforma do S2ID, a existência de fundo específico (rubrica direcionada), e a experiência/capacidade de trâmite de recursos financeiros entre os agentes da rede de GRD. 
Tabela 1 - Grupos de Indicadores e Subindicadores do Índice de Estruturação Organizacional-Institucional para governança da gestão de riscos de desastres.

\begin{tabular}{|c|c|c|c|}
\hline 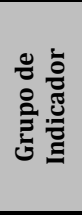 & Indicadores & 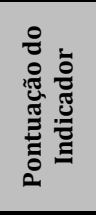 & 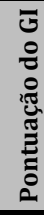 \\
\hline \multirow{2}{*}{ 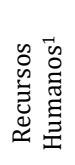 } & Em relação ao Gestor Municipal de Proteção e Defesa Civil: & 0,5000 & \multirow[b]{2}{*}{1,0} \\
\hline & $\begin{array}{l}\text { Em relação à equipe do Órgão Municipal de Proteção e Defesa Civil (não inclui o Gestor Municipal de Proteção e } \\
\text { Defesa Civil): }\end{array}$ & 0,5000 & \\
\hline \multirow{6}{*}{ 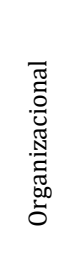 } & Existência de Plano Diretor Municipal de Defesa Civil & 0,1660 & \multirow{6}{*}{1,0} \\
\hline & Existência de Plano(s) de Contingência & 0,1660 & \\
\hline & Existência de Fundo Municipal de Defesa Civil & 0,1660 & \\
\hline & Existência de Conselho/Comissão Interna de Defesa Civil & 0,1660 & \\
\hline & Existência de Conselho/Comissão Externa de Defesa Civil (aberta à comunidade) & 0,1660 & \\
\hline & Existência de Núcleo Comunitário de Proteção e Defesa Civil (NUPDEC) & 0,1660 & \\
\hline \multirow{11}{*}{ 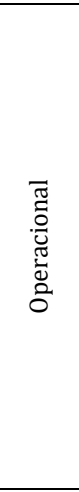 } & Tipos de ação que o Órgão Municipal de Proteção e Defesa Civil realiza & 0,0900 & \multirow{11}{*}{1,0} \\
\hline & Existência de Programas e/ou Ações contínuas em GRD & 0,0900 & \\
\hline & Realização de registro de ocorrências de desastres pelo Órgão Municipal de Proteção e Defesa Civil & 0,0900 & \\
\hline & Existência de mapeamento de áreas de risco de desastres & 0,0900 & \\
\hline & Existência de Plano Municipal de Redução de Riscos & 0,0900 & \\
\hline & Existência de Carta Geotécnica de Aptidão à Urbanização & 0,0900 & \\
\hline & Existência de Carta de Perigo & 0,0900 & \\
\hline & Existência de Mapeamento de Abrigos & 0,0900 & \\
\hline & Participação no Programa Cidades Resilientes da UNISDR & 0,0900 & \\
\hline & Realização de Exercícios Simulados & 0,0900 & \\
\hline & Realização de planejamento anual do Órgão Municipal de Defesa Civil. & 0,0900 & \\
\hline \multirow{17}{*}{ 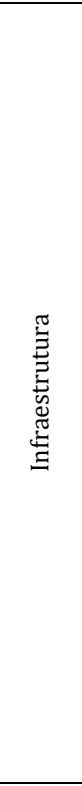 } & Possuir espaço físico próprio ara as atividades do Órgão Municipal de Defesa Civil; & 0,0588 & \multirow{17}{*}{1,0} \\
\hline & Existência de Centro Operacional (espaço integrado para os setores e instituições que gerem os desastres); & 0,0588 & \\
\hline & Existência de viatura(s) para mapeamento de risco para atividades do Órgão Municipal de Proteção e Defesa Civil; & 0,0588 & \\
\hline & Existência de computador(es) para atividades do Órgão Municipal de Proteção e Defesa Civil; & 0,0588 & \\
\hline & Existência de software(s) para mapeamento de risco para atividades do Órgão Municipal de Proteção e Defesa Civil; & 0,0588 & \\
\hline & Existência de Call Center para atividades específicas do Órgão Municipal de Proteção e Defesa Civil; & 0,0588 & \\
\hline & Existência de embarcação(ões) para atividades do Órgão Municipal de Proteção e Defesa Civil; & 0,0588 & \\
\hline & Existência de motosserra(s) para atividades do Órgão Municipal de Proteção e Defesa Civil; & 0,0588 & \\
\hline & Existência de Global Position System (GPS) para atividades do Órgão Municipal de Proteção e Defesa Civil; & 0,0588 & \\
\hline & Existência de máquina(s) fotográfica(s) para atividades do Órgão Municipal de Proteção e Defesa Civil; & 0,0588 & \\
\hline & Existência de rádio amador para atividades do Órgão Municipal de Proteção e Defesa Civil; & 0,0588 & \\
\hline & Existência de pluviômetro(s) para atividades do Órgão Municipal de Proteção e Defesa Civil; & 0,0588 & \\
\hline & Existência de pluviógrafos(s) (de leitura automática) para atividades do Órgão Municipal de Proteção e Defesa Civil; & 0,0588 & \\
\hline & $\begin{array}{c}\text { Existência de Estação(ões) Total(is) Robotizada(s) (ETR) para atividades do Órgão Municipal de Proteção e Defesa } \\
\text { Civil; }\end{array}$ & 0,0588 & \\
\hline & Existência de sirene(s) para atividades do Órgão Municipal de Proteção e Defesa Civil; & 0,0588 & \\
\hline & Existência de ferramentas (pás, enxadas, etc.) para atividades do Órgão Municipal de Proteção e Defesa Civil; & 0,0588 & \\
\hline & Existência de Sistema de Alerta e Alarme para atividades do Órgão Municipal de Proteção e Defesa Civil. & 0,0588 & \\
\hline \multirow{4}{*}{ 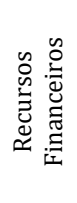 } & $\begin{array}{l}\text { Se possui experiência/capacidade (know-how) no trâmite de recursos financeiros entre agentes da rede de GRD no } \\
\text { período de } 2013 \text { a 2017; }\end{array}$ & 0,2500 & \multirow{4}{*}{1,0} \\
\hline & Existência de Fundo Municipal de Defesa Civil; & 0,2500 & \\
\hline & Utilização/manutenção de vínculo atualizado no Sistema Integrado de Informações sobre Desastres (S2ID); & 0,2500 & \\
\hline & Previsão de Recursos Financeiros no Plano Plurianual. & 0,2500 & \\
\hline
\end{tabular}

\footnotetext{
${ }^{1}$ Os indicadores deste GI possuem subindicadores, apresentados na Tabela 2.
} 
Tabela 2 - Critérios de aferição dos subindicadores do GI Recursos Humanos.

\begin{tabular}{|c|c|c|c|c|c|c|}
\hline \multicolumn{7}{|c|}{ GI Recursos Humanos } \\
\hline 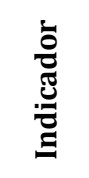 & 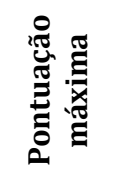 & Subindicador & 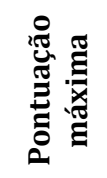 & \multicolumn{3}{|c|}{ Critérios de Aferição do Subindicador } \\
\hline \multirow{15}{*}{ 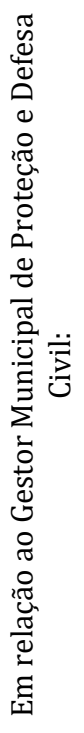 } & \multirow{15}{*}{0,5000} & \multirow{3}{*}{$\begin{array}{l}\text { Natureza do vínculo } \\
\text { empregatício com o } \\
\text { serviço público } \\
\text { municipal }\end{array}$} & \multirow{3}{*}{0,1250} & \multicolumn{3}{|c|}{ Para as respostas: } \\
\hline & & & & \multicolumn{3}{|c|}{ - efetivo/concursado; pontuação completa $(0,125)$; } \\
\hline & & & & \multicolumn{3}{|c|}{ - não efetivo/contratado; não pontuação (zero). } \\
\hline & & \multirow{3}{*}{$\begin{array}{l}\text { Exclusividade no } \\
\text { desempenho da } \\
\text { função }\end{array}$} & \multirow{3}{*}{0,1250} & \multicolumn{3}{|c|}{ Para as respostas: } \\
\hline & & & & \multicolumn{3}{|c|}{ - com exclusividade; pontuação completa $(0,125)$; } \\
\hline & & & & \multicolumn{3}{|c|}{ - acumula funções; não pontuação (zero). } \\
\hline & & & & \multicolumn{3}{|c|}{ Para as respostas, a pontuação é crescente: } \\
\hline & & & & \multicolumn{3}{|c|}{ - Ensino Fundamental; pontuação parcial $(0,025)$; } \\
\hline & & Nível de instrução & 01250 & \multicolumn{3}{|c|}{ - Ensino Médio; pontuação parcial $(0,05)$; } \\
\hline & & andamento & $0,1<30$ & \multicolumn{3}{|c|}{ - Ensino Superior; pontuação parcial $(0,075)$; } \\
\hline & & & & \multicolumn{3}{|c|}{ - Pós-Graduação Lato Sensu; a pontuação parcial $(0,1)$; } \\
\hline & & & & \multicolumn{3}{|c|}{ - Pós-Graduação Stricto Sensu; pontuação completa $(0,125)$. } \\
\hline & & \multirow{3}{*}{$\begin{array}{c}\text { Capacitação(ões) no } \\
\text { período de } 2013 \text { a } \\
2017\end{array}$} & \multirow{3}{*}{0,1250} & \multicolumn{3}{|c|}{ Para as respostas: } \\
\hline & & & & - participou de ca & ações no período; pontuação & ompleta $(0,125)$; \\
\hline & & & & - não participou & apacitações no período; não & ntuação (zero). \\
\hline & \multirow{23}{*}{0,5000} & \multirow{4}{*}{$\begin{array}{l}\text { Quantidade de } \\
\text { colaboradores*; }\end{array}$} & \multirow{4}{*}{0,1000} & & Para as respostas ${ }^{1}:$ & \\
\hline & & & & - mais que & laboradores; pontuação com & eta $(0,1)$; \\
\hline$\stackrel{\overrightarrow{0}}{0}$ & & & & - de $1 \mathrm{a}$ & aboradores; pontuação parc & $(0,5)$ \\
\hline. & & & & - não & laboradores; não pontuação & ero). \\
\hline 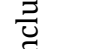 & & & & & Para as respostas: & \\
\hline 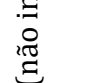 & & Tipo & & - mais que 4 colab & $\begin{array}{l}\text { ores efetivos/concursados; } p \\
\qquad(0,1)\end{array}$ & tuação completa \\
\hline$\sum_{3}^{-}$ & & colaboradores; & 0,1000 & - de 1 a 3 colabc & $\begin{array}{c}\text { res efetivos/concursados; } p \\
(0,5) ;\end{array}$ & tuação parcial \\
\hline$\stackrel{\infty}{\infty}:=$ & & & & - não há colabora & s efetivos/concursados; não & ontuação (zero). \\
\hline D. & & & & $\begin{array}{r}\text { A aferição é feit } \\
\text { inte }\end{array}$ & $\begin{array}{l}\text { média aritmética, mantend } \\
\text { estipulado para o subindica }\end{array}$ & $\begin{array}{l}\text { pontuação no } \\
\text { or: }\end{array}$ \\
\hline 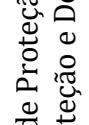 & & & & Valor do $=$ & $\begin{array}{c}\text { soma das pontuações } \\
\text { escolaridade dos } \\
\text { colaboradores }\end{array}$ & \\
\hline$\frac{0}{2}$ & & & & Subindicador $\mathrm{m}$ & número de colaboradores & \\
\hline$\because \frac{0}{\sigma}$ & & dos colaboradores; & 0,1000 & & Para as respostas: & \\
\hline$\sum_{\Sigma}^{\Xi} \stackrel{\widetilde{\pi}}{\Omega}$ & & & & - Ensin & damental; pontuação parcia & $0,02)$; \\
\hline 20. & & & & - En & Médio; pontuação parcial (0 & \\
\hline$\sigma^{\infty} \underbrace{2}$ & & & & - Ens & uperior; pontuação parcial ( & $06) ;$ \\
\hline & & & & - Pós-Grad & Lato Sensu; a pontuação pa & ial $(0,08)$; \\
\hline$\cong$ & & & & - Pós-Gradu & Stricto Sensu; pontuação co & pleta $(0,1)$. \\
\hline$\vec{d}$ & & Existência de & & & Para as respostas: & \\
\hline $\begin{aligned}-\pi \\
2 \\
2 \pi\end{aligned}$ & & profissionais de & 0,1000 & & n; pontuação completa $(0,1)$ & \\
\hline$\underset{\pi}{\pi}$ & & cargo específico; & & & não; não pontuação (zero). & \\
\hline$\stackrel{\Xi}{\Xi}$ & & & & & Para as respostas: & \\
\hline & & $\begin{array}{l}\text { Existencia de } \\
\text { voluntários. }\end{array}$ & 0,1000 & & n; pontuação completa $(0,1)$ & \\
\hline & & & & & não; não pontuação (zero). & \\
\hline
\end{tabular}

${ }^{1}$ Considera as recomendações de Brasil (2017). 
Os dados foram tabulados em um banco de dados alfanumérico no software Excel do Microsoft 365 , com a atribuição de valores e processamento dos subindicadores, dos indicadores e do IEOI. Para avaliação do IEOI foram adotadas as mesmas faixas de classificação utilizadas pelo Índice de Desenvolvimento Humano (Programa das Nações Unidas para o Desenvolvimento, 2013): a) muito baixo (de 0 a 0,499$)$; baixo (de 0,500 à 599$)$; b) médio $(0,600$ à 0,699$)$; c) alto $(0,700$ à 0,799$)$; e d) muito alto (acima de 0,800 ). Os GIs e IEOI da BHRI são apresentados por média aritmética dos valores dos municípios. O IEOI e suas análises também são representados graficamente nos softwares Corel Draw (versão X8) (gráfico) e ArcGIS 10.4 (mapa).

\section{Bacia Hidrográfica do Rio Itajaí: o estudo de caso}

Localizada em Santa Catarina e com cerca de $15.000 \mathrm{~km}^{2}$, a Bacia Hidrográfica do Rio Itajaí possui 1.531.575 habitantes (Instituto Brasileiro de Geografia e Estatística, 2020), com taxa de crescimento médio de 1,64\% ao ano no período de 2000 a 2010 (Instituto Brasileiro de Geografia e Estatística, 2010). Convergindo para o Oceano Atlântico, a BHRI possui todo seu território no Estado de Santa Catarina; ocupa cerca de 15\% do território estadual ( $95.730 \mathrm{~km}^{2}$ ) (Comitê do Itajaí, 2010); representa $21,11 \%$ da população estadual (7.252.502 habitantes no Estado) (Instituto Brasileiro de Geografia e Estatística, 2010) e um quarto do PIB catarinense em 2016 (25,5\%) (IBGE, 2016). Regionalmente, a BHRI se estrutura com o comitê de bacia hidrográfica e as Associações de Municípios (AMs). 0 Comitê de Gerenciamento da Bacia Hidrográfica do Rio Itajaí e bacias contíguas - o Comitê do Itajaí, é composto por 50 municípios. São três as AMs de maior representação na BHRI: do Alto Vale (AMAVI), com sede em Rio do Sul; da Foz do Itajaí (AMFRI), com sede em Itajaí; e do médio Vale (AMMVI), com sede em Blumenau (Figura 2).

Dados acerca do contexto dos municípios da BHRI, representados pelos municípios que abrangem o Comitê do Itajaí, são apresentados na Tabela 3, como forma de caracterizar a região. Os dados trazem destaque aos municípios sede das Associações de Municípios, considerados polos regionais. Estes dados serão utilizados na análise de Correlação com o IEOI afim de encontrar variáreis explicativas, que mostrem correlação no comportamento dos dados.

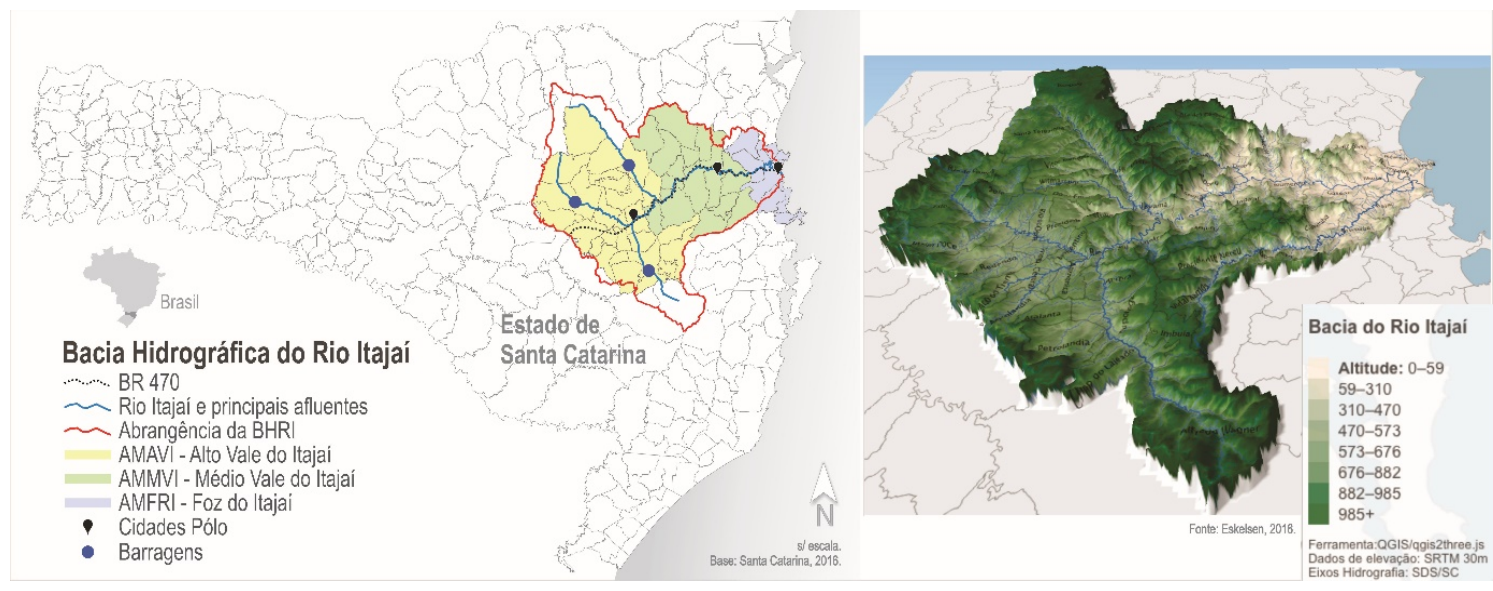

Figura 2 - Localização, Associações de Municípios e relevo da BHRI. Base: Santa Catarina (2016) e Eskelsen (2016).

A bacia hidrográfica do Rio Itajaí possui registro de eventos de inundações desde sua colonização, em 1850. Entre diferentes projetos e intervenções, em 1973 o município de Blumenau instituiu a Comissão Municipal de Defesa Civil (Blumenau, 2018), mesmo ano em que é instituída a Defesa Civil do Estado de Santa Catarina. A grande enchente de 1983 teve alto impacto na região e repercussão nacional: $30 \%$ das residências foram alagadas e 50 mil pessoas foram desalojadas (Ouriques et al., 2018). A criação do Centro de Operações do Sistema de Alerta da Bacia do Itajaí em 1984 - primeiro sistema de previsão e alerta de cheias do Brasil, vinculados à Universidade Regional de Blumenau marcaram o início de estudos locais sobre riscos de desastres (Frank \& Bohn, 2018). Com a instituição da Política Nacional de Recursos Hídricos (Brasil, 1997), em 1998 é criado o Comitê de Gerenciamento da Bacia Hidrográfica do Rio Itajaí e bacias contíguas - o Comitê do Itajaí (2010). 
Em novembro de 2008, Santa Catarina foi atingida por chuvas intensas e prolongadas que desencadearam inundações e deslizamentos com 135 mortes, 103.000 pessoas afetadas, 25.000 desalojados e 5.029 desabrigados (Ouriques et al., 2018). Na BHRI, 11 municípios decretaram estado de calamidade pública, e 15, de situação de emergência. Esse episódio desencadeou a elaboração do Plano Integrado de Prevenção e Mitigação de Desastres Naturais na (2009) pelo Comitê do Itajaí.

Tabela 3 - Dados do contexto regional da bacia hidrográfica do Rio Itajaí.

\begin{tabular}{|c|c|c|c|c|c|c|c|c|c|c|c|c|c|c|c|}
\hline \multirow{3}{*}{ Municípios BHRI } & \multirow{3}{*}{ 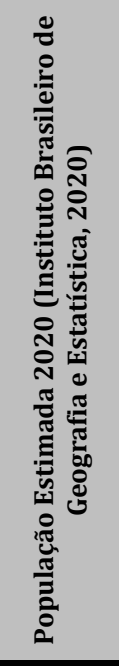 } & \multirow{3}{*}{ 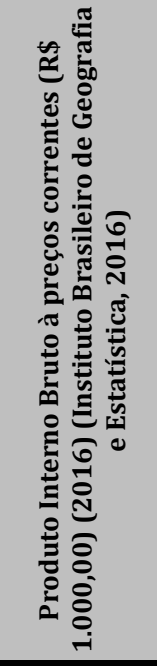 } & \multirow{3}{*}{ 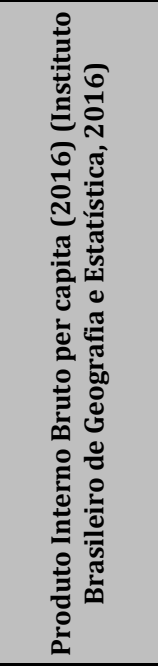 } & \multirow{3}{*}{ 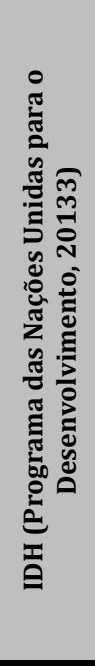 } & \multicolumn{9}{|c|}{$\begin{array}{l}\text { Registros de desastres naturais nos municípios } \\
\text { da BHRI, no período de } 1991 \text { à } 2012 \\
\text { (Universidade Federal de Santa Catarina, 2013) }\end{array}$} & \multirow{3}{*}{ 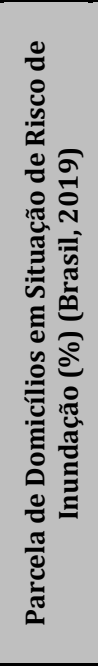 } & \multirow{3}{*}{ 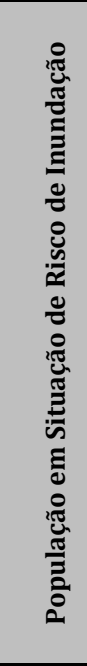 } \\
\hline & & & & & \multirow[b]{2}{*}{ 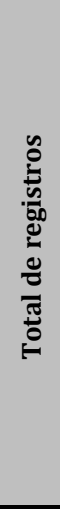 } & \multicolumn{8}{|c|}{ registros por tipo de desastres } & & \\
\hline & & & & & & 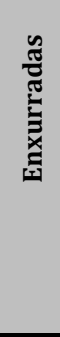 & 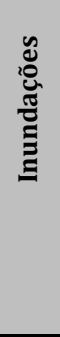 & 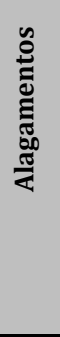 & 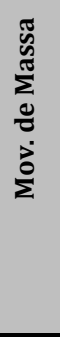 & 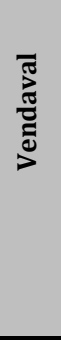 & 远 & 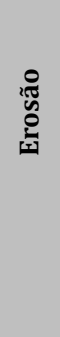 & 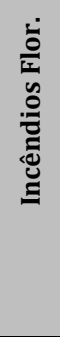 & & \\
\hline Agrolândia $(*)$ & 11.013 & 243.160 & $22.980,77$ & 0,725 & 15 & 7 & 1 & 0 & 0 & 1 & 1 & 0 & 0 & 31,3 & 3447 \\
\hline Agronômica $\left(^{*}\right)$ & 5.509 & 155.556 & $28.610,56$ & 0,741 & 15 & 6 & 5 & 0 & 0 & 1 & 1 & 0 & 0 & SD & SD \\
\hline Alfredo Wagner $(*)$ & 10.086 & 229.704 & $23.062,64$ & 0,668 & 21 & 13 & 3 & 0 & 0 & 3 & 1 & 0 & 0 & 57,3 & 5779 \\
\hline Apiúna $(* * *)$ & 10.848 & 414.858 & $39.352,86$ & 0,708 & 9 & 7 & 0 & 0 & 0 & 0 & 1 & 0 & 0 & 1,1 & 119 \\
\hline Ascurra $(* * *)$ & 7.978 & 192.518 & $24.440,55$ & 0,742 & 8 & 6 & 1 & 0 & 0 & 0 & 0 & 0 & 0 & 3,3 & 263 \\
\hline Atalanta $(*)$ & 3.195 & 99.533 & $30.587,87$ & 0,733 & 19 & 10 & 2 & 0 & 0 & 1 & 4 & 0 & 0 & 16,1 & 514 \\
\hline Aurora $(*)$ & 5.683 & 166.782 & $29.321,67$ & 0,733 & 22 & 13 & 1 & 0 & 0 & 1 & 2 & 0 & 0 & 25,3 & 1438 \\
\hline Balneário Piçarras $\left({ }^{* *}\right)$ & 23.772 & 282.332 & $16.535,80$ & 0,756 & 13 & 8 & 0 & 1 & 0 & 2 & 1 & 1 & 0 & 0,9 & 214 \\
\hline Benedito Novo $\left({ }^{* * *}\right)$ & 11.775 & 294.074 & $25.739,56$ & 0,740 & 13 & 9 & 4 & 0 & 0 & 0 & 0 & 0 & 0 & 13,6 & 1601 \\
\hline Blumenau $(* * *)$ & 361.855 & 16.008 .744 & $45.934,42$ & 0,806 & 31 & 16 & 7 & 0 & 1 & 3 & 3 & 0 & 1 & 9,1 & 32929 \\
\hline Botuverá $(* * *)$ & 5.322 & 282.670 & $55.425,59$ & 0,724 & 10 & 6 & 3 & 0 & 0 & 1 & 0 & 0 & 0 & 0,9 & 48 \\
\hline Braço do Trombudo (*) & 3.769 & 137.874 & $37.172,77$ & 0,780 & 9 & 5 & 1 & 0 & 0 & 1 & 1 & 0 & 0 & 4,5 & 170 \\
\hline Brusque $(* * *)$ & 137.689 & 5.883 .938 & $45.676,36$ & 0,795 & 16 & 12 & 2 & 0 & 0 & 2 & 0 & 0 & 0 & 0 & 0 \\
\hline Chapadão do Lageado ${ }^{1}(*)$ & 3.006 & 82.487 & $27.933,29$ & 0,704 & 21 & 11 & 0 & 0 & 0 & 2 & 5 & 0 & 0 & 0 & 0 \\
\hline Dona Emma $(*)$ & 4.186 & 101.237 & $24.806,94$ & 0,742 & 21 & 8 & 2 & 0 & 1 & 1 & 2 & 0 & 0 & 0 & 0 \\
\hline Doutor Pedrinho ${ }^{* * *}$ ) & 4.115 & 112.894 & $27.923,23$ & 0,716 & 4 & 1 & 3 & 0 & 0 & 0 & 0 & 0 & 0 & 26,5 & 1090 \\
\hline Gaspar $(* * *)$ & 70.793 & 2.824 .094 & $41.905,48$ & 0,765 & 22 & 12 & 2 & 0 & 3 & 3 & 1 & 0 & 1 & 24,6 & 17415 \\
\hline Guabiruba $(* * *)$ & 24.382 & 902.535 & $39.703,30$ & 0,754 & 14 & 8 & 2 & 0 & 0 & 2 & 2 & 0 & 0 & 6,2 & 1512 \\
\hline Ibirama $(*)$ & 19.096 & 421.545 & $22.517,21$ & 0,737 & 9 & 4 & 1 & 0 & 1 & 0 & 1 & 0 & 0 & 1,6 & 306 \\
\hline Ilhota $(* *)$ & 14.359 & 681.625 & $49.189,96$ & 0,738 & 26 & 14 & 2 & 0 & 0 & 7 & 2 & 0 & 0 & 2,5 & 359 \\
\hline Imbuia $(*)$ & 6.241 & 123.573 & $20.148,90$ & 0,713 & 18 & 7 & 0 & 0 & 0 & 2 & 5 & 0 & 0 & 1,6 & 100 \\
\hline Indaial $(* * *)$ & 70.900 & 2.499 .704 & $37.591,23$ & 0,777 & 10 & 5 & 3 & 0 & 0 & 2 & 0 & 0 & 0 & 1,1 & 780 \\
\hline Itaiópolis $\left.{ }^{1}{ }^{*}\right)$ & 21.780 & 704.218 & $32.745,17$ & 0,708 & 27 & 9 & 4 & 0 & 1 & 4 & 6 & 0 & 0 & 0 & 0 \\
\hline Itajaí $(* *)$ & 223.112 & 21.913 .882 & $103.068,37$ & 0,795 & 23 & 13 & 3 & 0 & 0 & 0 & 0 & 0 & 0 & 81,8 & 20000 \\
\hline Ituporanga $(*)$ & 25.355 & 831.607 & $33.774,95$ & 0,748 & 25 & 12 & 3 & 0 & 0 & 3 & 3 & 0 & 0 & 5,5 & 1395 \\
\hline José Boiteux $\left({ }^{*}\right)$ & 5.007 & 108.751 & $22.253,16$ & 0,694 & 21 & 11 & 1 & 0 & 1 & 1 & 0 & 0 & 0 & 0 & 0 \\
\hline Laurentino $(*)$ & 7.063 & 257.418 & $37.911,29$ & 0,749 & 11 & 5 & 3 & 0 & 0 & 0 & 1 & 0 & 0 & 22,8 & 1610 \\
\hline
\end{tabular}




\section{Tabela 3. Continuação ...}

\begin{tabular}{|c|c|c|c|c|c|c|c|c|c|c|c|c|c|c|c|}
\hline \multirow{3}{*}{ Municípios BHRI } & \multirow{3}{*}{ 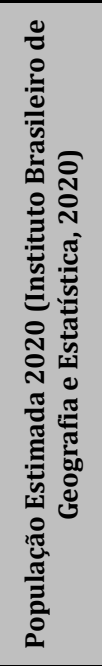 } & \multirow{3}{*}{ 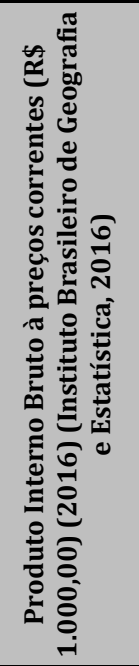 } & \multirow{3}{*}{ 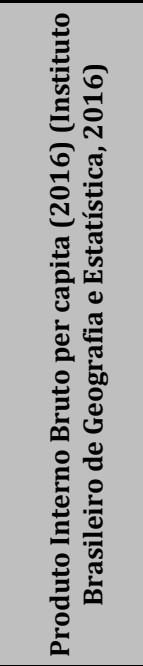 } & \multirow{3}{*}{ 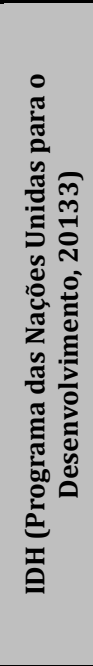 } & \multicolumn{9}{|c|}{$\begin{array}{l}\text { Registros de desastres naturais nos municípios } \\
\text { da BHRI, no período de } 1991 \text { à } 2012 \\
\text { (Universidade Federal de Santa Catarina, 2013) }\end{array}$} & \multirow{3}{*}{ 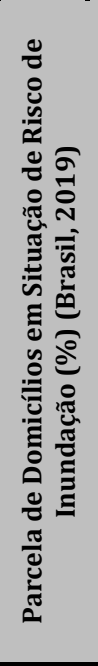 } & \multirow{3}{*}{ 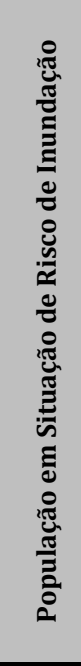 } \\
\hline & & & & & \multirow[b]{2}{*}{ 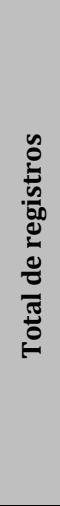 } & \multicolumn{8}{|c|}{ registros por tipo de desastres } & & \\
\hline & & & & & & 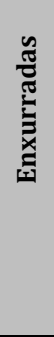 & 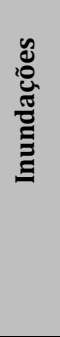 & 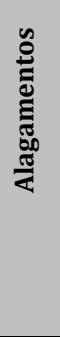 & 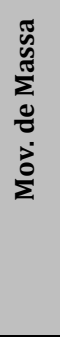 & 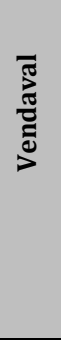 & 苞 & 趈 & 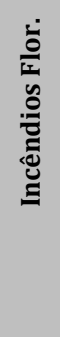 & & \\
\hline Lontras $(*)$ & 12.315 & 314.188 & $26.684,86$ & 0,704 & 12 & 5 & 3 & 0 & 0 & 0 & 1 & 0 & 0 & 33,3 & 4101 \\
\hline Luiz Alves $(* *)$ & 13.107 & 570.948 & $45.995,95$ & 0,737 & 9 & 6 & 1 & 0 & 0 & 1 & 1 & 0 & 0 & 48,9 & 6409 \\
\hline Mirim Doce $\left(^{*}\right)$ & 2283 & 55.138 & $23.225,75$ & 0,708 & 13 & 8 & 1 & 0 & 0 & 0 & 0 & 0 & 0 & 1,7 & 39 \\
\hline Navegantes $^{1}(* *)$ & 83.626 & 4.106 .551 & $53.237,11$ & 0,736 & 19 & 11 & 2 & 1 & 0 & 3 & 2 & 0 & 0 & SD & SD \\
\hline Penha (**) & 33.284 & 673.705 & $21.714,92$ & 0,743 & 8 & 5 & 1 & 0 & 0 & 2 & 0 & 0 & 0 & 1,5 & 499 \\
\hline Petrolândia $\left(^{*}\right)$ & 5.905 & 167.122 & $27.756,51$ & 0,716 & 16 & 9 & 0 & 0 & 0 & 2 & 1 & 0 & 0 & 1,8 & 106 \\
\hline Pomerode $^{1}(* * *)$ & 34.010 & 1.918 .862 & $59.345,03$ & 0,780 & 12 & 8 & 1 & 1 & 1 & 0 & 1 & 0 & 0 & 0,8 & 272 \\
\hline Pouso Redondo (*) & 17.712 & 520.561 & $30.698,90$ & 0,720 & 11 & 3 & 3 & 0 & 0 & 0 & 2 & 0 & 0 & 0,1 & 18 \\
\hline Presidente Getúlio $(*)$ & 17.726 & 625.706 & $36.814,88$ & 0,759 & 22 & 9 & 4 & 1 & 2 & 1 & 2 & 0 & 0 & 26,4 & 4680 \\
\hline Presidente Nereu $\left({ }^{*}\right)$ & 2.283 & 55.114 & $23.921,18$ & 0,737 & 14 & 9 & 1 & 0 & 0 & 1 & 1 & 0 & 0 & 0 & 0 \\
\hline Rio do Campo $(*)$ & 5.902 & 162.911 & $26.958,59$ & 0,729 & 28 & 11 & 5 & 0 & 0 & 1 & 4 & 0 & 0 & 1,5 & 89 \\
\hline Rio do Oeste $\left(^{*}\right)$ & 7.520 & 194.681 & $26.086,09$ & 0,754 & 19 & 10 & 4 & 0 & 1 & 0 & 1 & 0 & 0 & SD & SD \\
\hline Rio do Sul $(*)$ & 72.006 & 2.571 .376 & $37.165,06$ & 0,802 & 23 & 12 & 7 & 0 & 0 & 2 & 0 & 0 & 0 & 18 & 12961 \\
\hline Rio dos Cedros ( ${ }^{* * *}$ ) & 11.808 & 310.212 & $27.137,80$ & 0,729 & 11 & 8 & 2 & 0 & 0 & 0 & 1 & 0 & 0 & 5,3 & 626 \\
\hline Rodeio ${ }^{* * *}$ ) & 11.600 & 273.837 & $23.836,77$ & 0,754 & 10 & 8 & 2 & 0 & 0 & 0 & 0 & 0 & 0 & 2 & 232 \\
\hline Salete $\left(^{*}\right)$ & 7.659 & 180.668 & $23.666,20$ & 0,744 & 23 & 12 & 0 & 0 & 0 & 5 & 1 & 0 & 0 & 0,5 & 38 \\
\hline Santa Terezinha $(*)$ & 8.773 & 192.897 & $21.806,09$ & 0,669 & 25 & 9 & 1 & 0 & 1 & 0 & 2 & 0 & 0 & 0 & 0 \\
\hline Taió $(*)$ & 18.486 & 573.530 & $31.407,39$ & 0,761 & 26 & 13 & 5 & 0 & 0 & 0 & 2 & 0 & 0 & 15,6 & 2884 \\
\hline Timbó $(* * *)$ & 44.977 & 1.832 .021 & $42.803,22$ & 0,784 & 13 & 5 & 3 & 0 & 0 & 0 & 3 & 0 & 0 & 44,7 & 20105 \\
\hline Trombudo Central $(*)$ & 7.434 & 232.352 & $32.221,92$ & 0,775 & 7 & 3 & 1 & 0 & 0 & 0 & 4 & 0 & 0 & 10,6 & 788 \\
\hline Vidal Ramos $(*)$ & 6.329 & 250.107 & $39.349,76$ & 0,700 & 21 & 14 & 0 & 0 & 0 & 1 & 0 & 0 & 0 & SD & SD \\
\hline Vitor Meireles $(*)$ & 4.943 & 117.880 & $23.314,81$ & 0,673 & 11 & 6 & 1 & 0 & 0 & 0 & 0 & 0 & 0 & 16,8 & 830 \\
\hline Witmarsum $\left({ }^{*}\right)$ & 3.998 & 120.808 & $30.881,48$ & 0,710 & 14 & 5 & 1 & 0 & 1 & 0 & 2 & 0 & 0 & 9,5 & 380 \\
\hline
\end{tabular}

${ }^{1}$ Mumicípios que não participaram do Levantamento de Dados GRD na BHRI..

SD - sem dados do município.

\begin{tabular}{c|c|c|l|l|l|l|l|l}
\hline Legenda por AMs: & $(*)$ & AMAVI - Associação dos Municípios do Alto Vale do Itajaí & & & & & & \\
\hline & $(* *)$ & & & & \\
\hline & $(* * *)$ & AMMVI - Associação dos Municípios do Médio Vale do Itajaí & & \\
\hline
\end{tabular}

Fonte: Instituto Brasileiro de Geografia e Estatística (2016, 2020), Programa das Nações Unidas para o Desenvolvimento (2013), Universidade Federal de Santa Catarina (2013), Brasil (2019).

Em 2013, Blumenau (representante do desastre de 2008 no Vale do Itajaí em Santa Catarina), Petrópolis e Nova Friburgo (representantes do desastre de 2011 na Região Serrana do Rio de Janeiro) passam a integrar o Projeto de Fortalecimento da Estratégia Nacional de Gestão Integrada de Riscos 
em Desastres Naturais (Gides), numa parceria entre a Agência de Cooperação Internacional do Japão (Jica), a Agência Brasileira de Cooperação (ABC), o Ministério da Integração, Ministério das Cidades, Ministério da Ciência Tecnologias e Inovação, e Ministério de Minas e Energia. A participação no projeto trouxe capacitação à equipe envolvida e o desenvolvimento de seis manuais para fortalecer a capacidade de gestão de riscos e resposta a desastres de movimento de massa no Brasil. Em 2018, o Governo do Estado implantou o Centro Regional de Gerenciamento de Desastres em Blumenau (Cigerd).

Embora verifique-se municípios em que que há maior suscetibilidade à riscos de desastres relacionado ao relevo ou outras características físicas, percebe-se que todos os municípios apresentam registros de desastres no período de 1991 à 2012 (Tabela 3). Jansen \& Vieira (2016), com dados do Censo Munic 2013 do IBGE apontam que todos os municípios abrangidos pelo Comitê do Itajaí declaram a incidência de algum tipo de desastre (as enxurradas - apresentada no Brasil como inundações bruscas, inundações graduais e/ou deslizamentos) no período de cinco anos que antecederam o estudo.

\section{RESULTADOS}

Para facilitar a compreensão dos resultados e suas análises, esses serão apresentados nos subitens: IEOI e a Análise do Contexto Regional, a Análise de Correlação com dados municipais e a Análise da Matriz de Resiliência Local.

\section{O IEOI e a Análise do Contexto Regional}

O IEOI de governança e gestão de riscos de desastres da BHRI é apresentado sob forma da Figura 3. A imagem permite visualizar os resultados do IEOI de cada município e da BHRI. Os municípios são visualizados de forma radial, em ordem decrescente de valor do IEOI, sendo possível identificar cada GI que compõe o Índice, em diferentes cores, nos diferentes municípios. A representação utiliza o gráfico do tipo 'rose chart', em que os valores de GIs tem sua representação em barras em tamanhos proporcionais. Quanto maior o valor do Índice, melhor estruturado é o município para a governança e a gestão do risco de desastres. Finalmente, o IEOI da BHRI é apresentado no centro, com indicação da importância de cada GI na sua composição.

A análise dos IEOIs dos municípios da BHRI aponta o contraste entre as realidades de estruturação organizacional-institucional para GRD nestas unidades politico-administrativas: a amplitude ente o município de menor pontuação (Dona Emma - 0,151) e o de maior pontuação (Blumenau - 0,890) mostram posições extremas de classificação (muito baixo e muito alto). A maioria dos municípios (31 dos 46 participantes do levantamento - 67,39\%) apresentam IEOI menor que 0,5, sendo classificados na faixa muito baixo (de 0 a 0,499). Apenas um município apresentou IEOI muito alto (Blumenau - 0,890), e dois municípios IEOI alto (Itajaí - 0,794; Rio do Sul - 0,764). Apresentaram IEOI médio três municípios (Gaspar, Brusque e Ituporanga), e IEOI baixo, seis municípios (Taió, Ibirama, Pouso Redondo, Salete, Mirim Doce e Ascurra).

São observados casos em que municípios atingem a mesma pontuação de IEOI e apresentam pontuações bastante diferentes entre seus GIs - como, Balneário Piçarras e Botuverá $(0,414)$; assim como os que apresentam mesmo IEOI e valores idênticos em seus GIs - como Rodeio e Timbó $(0,488)$. 0 GI Recursos Financeiros atinge a maior amplitude $(1,0)$, variando entre a pontuação máxima (atingida por Blumenau e Luiz Alves) e nula (Dona Emma, Imbuia, Penha). O GI Organizacional também atingiu valor nulo nos municípios de Trombudo Central e Witmarsum. Os três municípios que apresentaram maior IEOI (Blumenau, Itajaí e Rio do Sul) apresentaram todos os GIs acima de 0,700.

O IEOI da BHRI apresenta classificação muito baixo (pontuação 0,441), assim como seus cinco GIs. Considerando que a BHRI a) apresenta recorrência histórica de desastres deflagrados pela água; b) que os danos e perdas gerados por estes desastres tem magnitude considerável; c) que apresenta municípios considerados referência nacional e na América Latina em relação estudos e práticas de gestão associados à esses desastres (caso de Blumenau); a expectativa por um IEOI mais elevado na BHRI não se confirma.

O GI de menor desempenho na BHRI foi o Operacional (0,360 - muito baixo), seguido em ordem crescente pelo Organizacional (0,408 - muito baixo), de Infraestrutura (0,460 - muito baixo), Recursos Humanos $(0,482)$ e, e em melhor colocação Recursos Financeiros $(0,495$ - baixo).

Embora o GI de Recursos Humanos seja o segundo de maior pontuação da BHRI, foi o que apresentou maiores críticas em contato informal com os Gestores Municipais de Defesa Civil (GMDC) 
durante o levantamento de dados. Pôde-se perceber que um GMDC capacitado e envolvido com o processo é capaz de alcançar um IEOI considerável (considerando os demais GIs), mesmo com baixa pontuação no indicador referente à equipe no GI de Recursos Humanos. Claro que esta situação também apresenta limitações. Embora não tenha se observado relação negativa expressiva entre a baixa pontuação no GI de Recursos Humanos e o desempenho dos demais GIs, cabe destacar que a limitação de recursos humanos dificulta a implementação de programas e projetos (ações contínuas), característicos do GI Operacional. 0 GI Operacional foi o que obteve a menor pontuação na BHRI e tem indicadores de relação direta com os processos de prevenção, mitigação e preparação na gestão do risco.

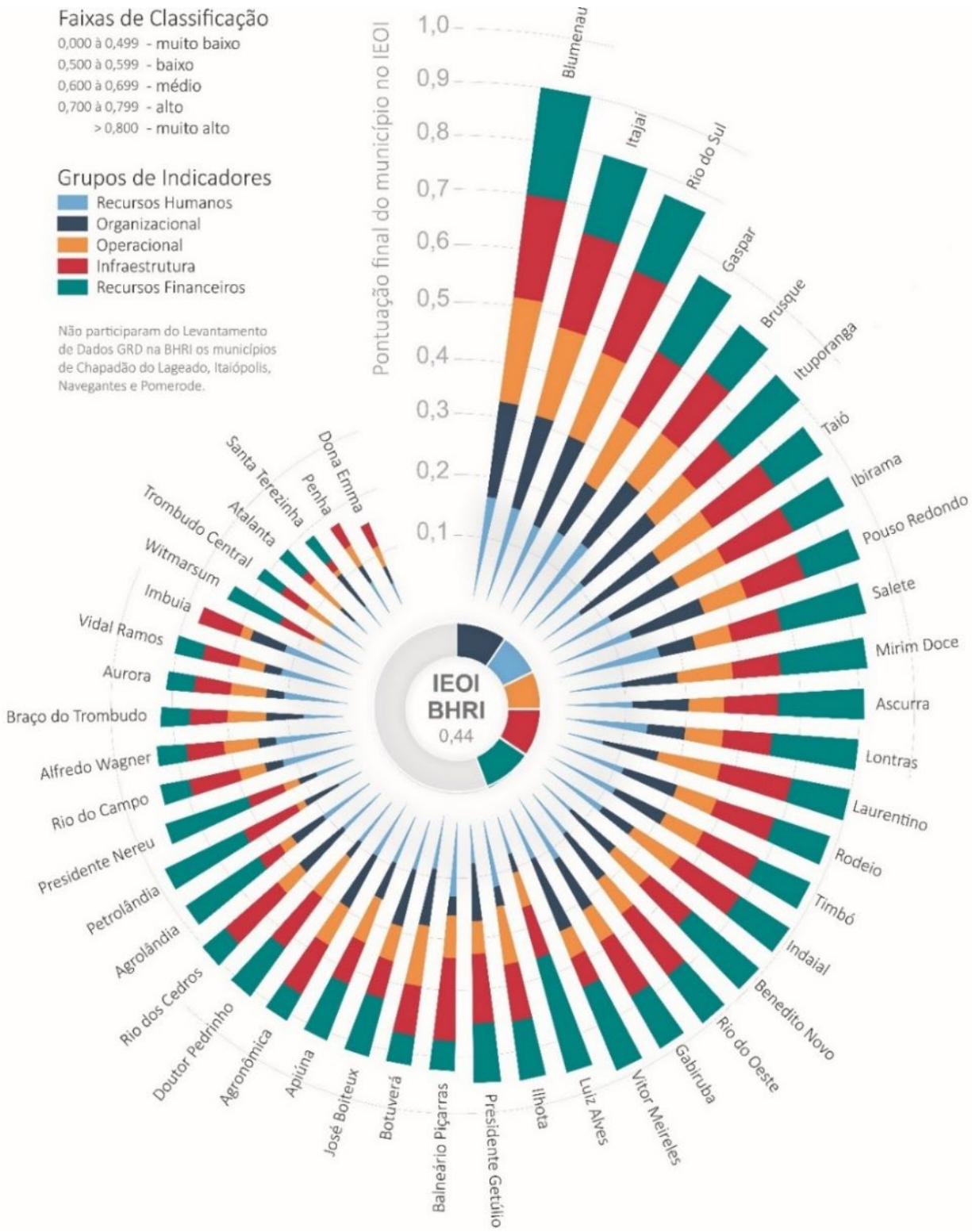

Figura 3 - Espacialização do Índice de Estruturação Organizacional-Institucional (IEOI) para GRD da bacia hidrográfica do Rio Itajaí e seus municípios.

Partindo dos índices espacializados na Figura 3, a Figura 4A representa a classificação dos IEOIs dos municípios por AMs: AMAVI, AMFRI e AMMVI - adotando uma tonalidade por município, sobrepostas ao gráfico da Figura 3; e a Figura 4B representa a média dos GIs e o valor final do IEOI por AM, em um gráfico de barras. A Figura 4 introduz a análise Macro dos resultados, considerando o nível territorial regional.

As AMs apresentam pontuações de IEOI muito próximas, sendo que a AMMVI $(0,518)$ obteve maior pontuação, com classificação de IEOI baixo; seguida pela AMFRI $(0,454)$ e AMAVI $(0,406)$, com 
IEOI muito baixo. Nas AMs as menores pontuações de GIs ocorrem no Operacional para a AMMVI $(0,445)$ e AMAVI $(0,308)$, e Organizacional para a AMFRI $(0,299)$. A AMMVI atinge suas maiores pontuações nos GIs de Infraestrutura $(0,556)$ e Recursos Financeiros $(0,558)$, a AMFRI em Infraestrutura $(0,529)$ e a AMAVI em Recursos Financeiros $(0,472)$.

$\mathrm{Na}$ análise dos municípios por AMs (sentido montante à jusante) pode-se verificar que na:

- $\quad$ AMAVI: Rio do Sul apresenta a terceira melhor classificação da BHRI (alto), Ituporanga apresenta IEOI médio $(0,602)$, cinco municípios com classificação baixo, e 20 municípios com IEOI muito baixo. Destacamos que as piores classificações (com exceção de Penha e Alfredo Wagner) são ocupadas por municípios da AMAVI.

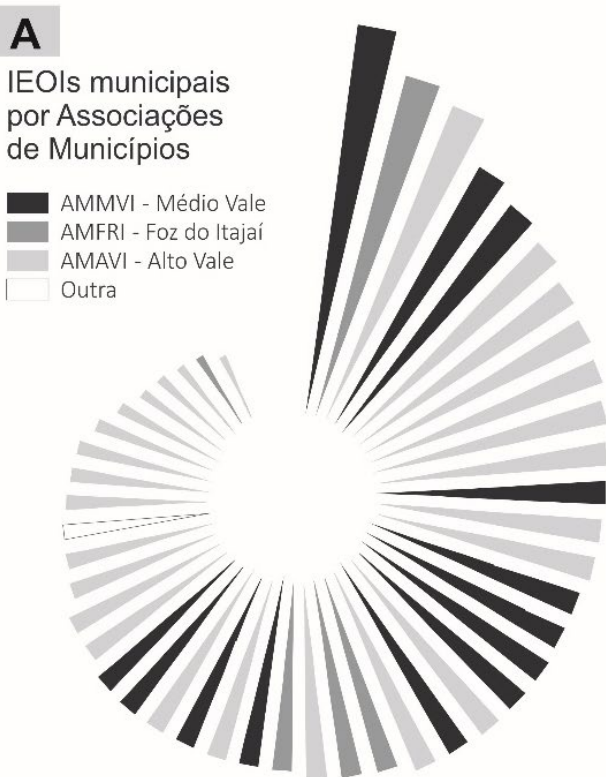

\section{B}

IEOI das Associações de Municípios

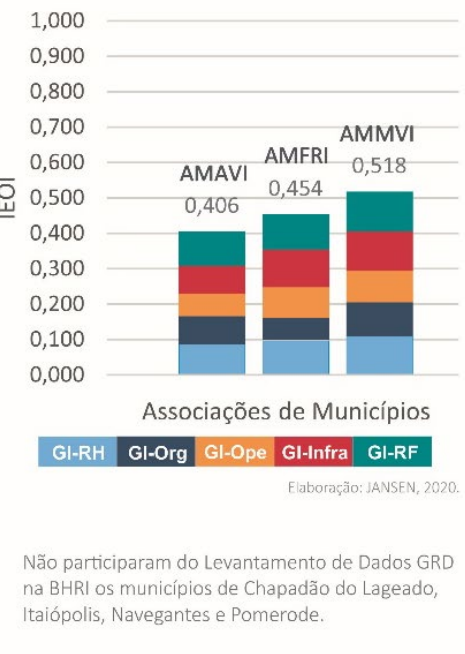

Figura 4 - Análise do Índice de Estruturação Organizacional-Institucional (IEOI) de GRD por Associação de Município da bacia hidrográfica do Rio Itajaí.

- AMMVI: Blumenau atinge a melhor classificação da BHRI (muito alto), e Gaspar e Brusque na quarta e quinta colocação (médio), Ascurra atinge IEOI baixo, e os outros nove, muito baixo. Ilhota e Luiz Alves, fortemente impactados com o desastre de 2008, apresentam IEOI muito baixo;

- AMFRI: Itajaí apresenta a segunda melhor classificação na BHRI (alto), e os outros quatro municípios são classificados como muito baixo. Destacamos que Penha tem a penúltima pontuação entre os municípios $(0,174)$ da BHRI;

Os municípios que atingiram maior pontuação em cada AMs são suas respectivas sedes e polos regionais: Blumenau na AMMVI, Itajaí na AMFRI e Rio do Sul na AMAVI. Salienta-se que esses polos podem não estar compreendendo sua responsabilidade na região como contribuição aos municípios de seu entorno, pois trata-se de uma relação de duplo sentido, na qual os municípios do entorno contribuem constantemente para sua manutenção como polo. Assumir estes papeis principais na rede de governança de risco de desastres representa aceitar sua influência na região, retroalimentando o sistema. É necessário que os municípios polo assumam que a GRD ultrapassa limites políticoadministrativos e contribuam para os municípios que o cercam (contribuição que pode ocorrer sem qualquer prejuízo financeiro).

Dando continuidade à análise em nível territorial regional, foi gerada a espacialização das categorias de IEOI sobre os municípios da BHRI, exibindo os municípios em cores que variam segundo a classificação por faixa de IEOI, como se observa na Figura 5.

Os municípios que apresentam IEOI médio (amarelo), alto (laranja suave) e muito alto (laranja intenso) não apresentam uma distribuição espacial homogênea no território da BHRI (Figura 5). Porém, esses municípios são drenados diretamente pelo Rio Itajaí: ao sul, Ituporanga drenado pelo afluente Rio Itajaí do Sul; na sequência Rio do Sul, que recebe o encontro dos afluentes Rio Itajaí do Oeste e Rio Itajaí do Sul, mesmo ponto em que inicia o Rio Itajaí-Açú que passa por Blumenau, Gaspar e Itajaí, onde encontra o Oceano Atlântico pouco depois de encontrar o Rio Itajaí-Mirim, que antecedeu 
Brusque. Com exceção de Ituporanga, esses municípios têm grande representatividade populacional na BHRI e estão em regiões em que o relevo aumenta a suscetibilidade à inundações devido à trechos de baixa declividade ou encontro de afluentes.

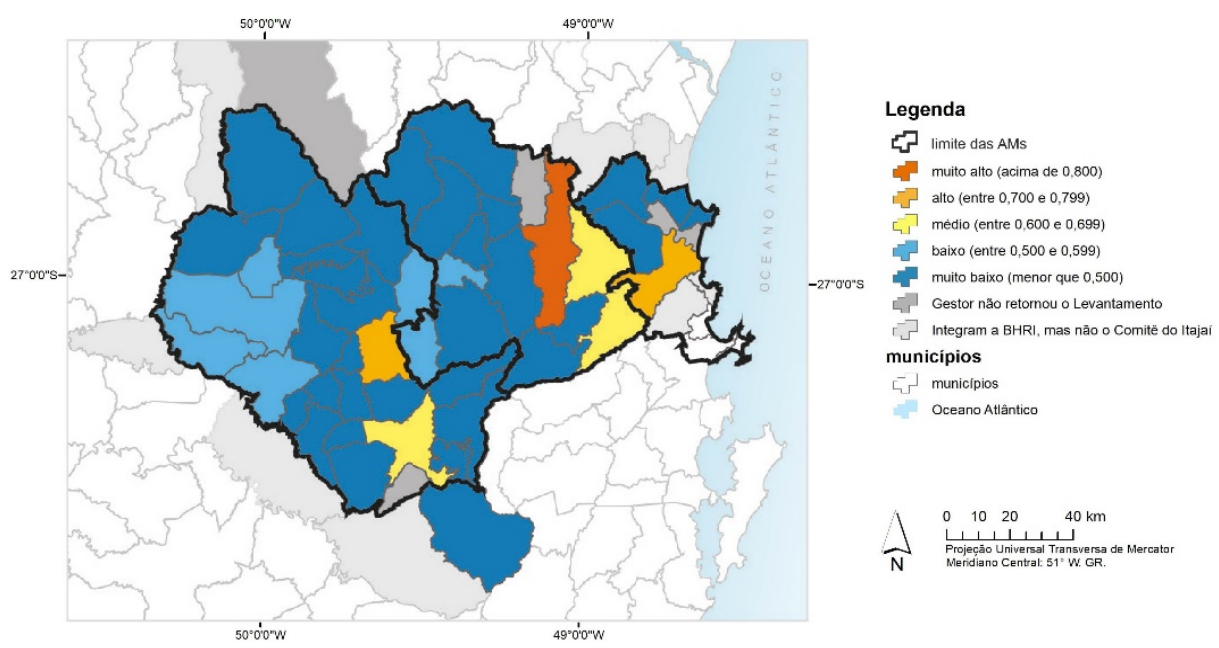

Figura 5 - Análise espacial do Índice de Estruturação Organizacional-Institucional (IEOI) de GRD na bacia hidrográfica do Rio Itajaí. Base: INPE (2015) [[Q15: Q15]].

\section{Análise de Correlação}

A correlação entre os dados dos IEOI e as características dos municípios da BHRI apresentados na Tabela 3, mostra à que medida os IEOI têm variação explicada por alguns fatores sociais, econômicos e físicos. A Tabela 4 exibe os resultados dessa análise de correlação, em que R (Rquadrado) tem valores que representam a porcentagem da variação da variável resposta que é explicada por um modelo linear, ou seja, a porcentagem à qual os valores de IEOI estão relacionadas à determinado tipo de dados.

Tabela 4 - Análise da correlação entre o Índice de Estruturação Organizacional-Institucional (IEOI) de GRD e as características do contexto regional da bacia Hidrográfica do Rio Itajaí.

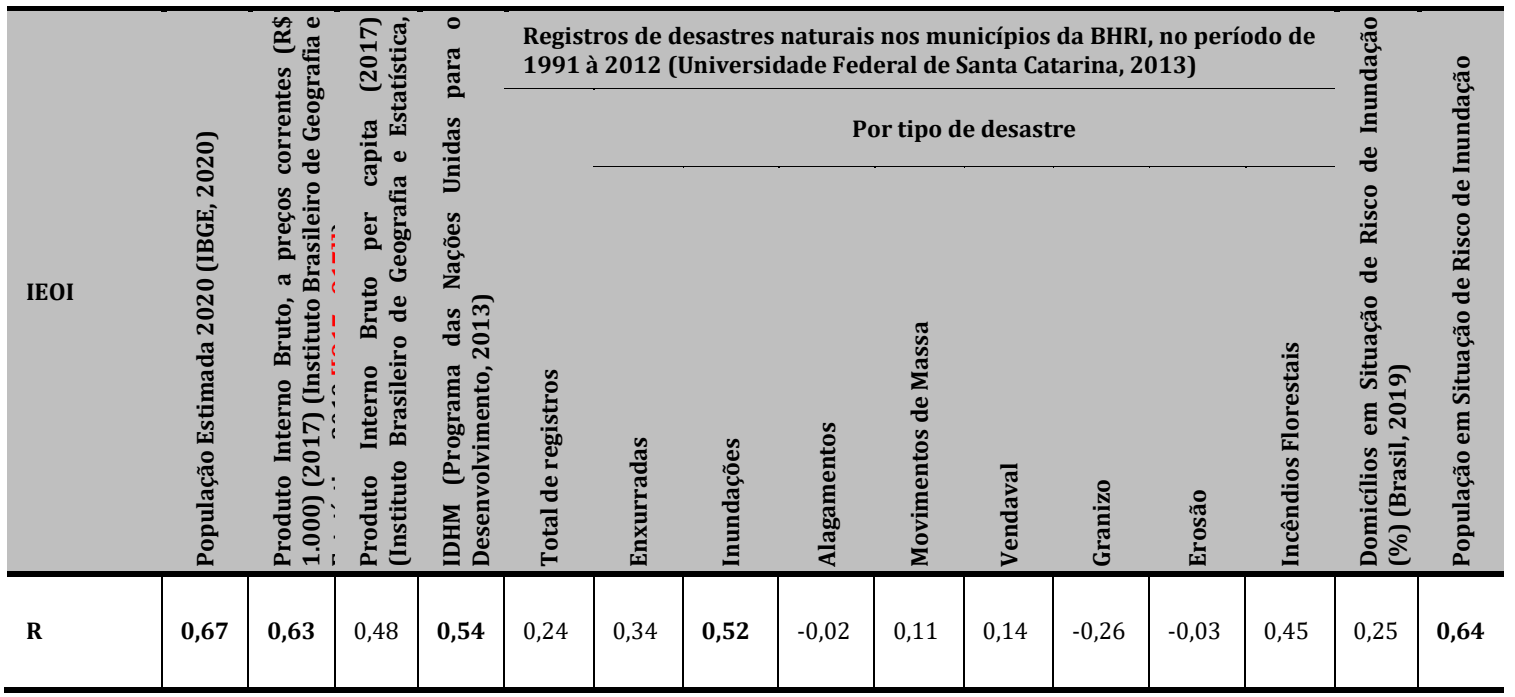

O IEOI apresenta maior correlação com o indicador da variação da população estimada por município $(R=0,67)$, seguido pela população em situação de risco de inundação $(R=0,64)$ e o PIB a preços correntes (variância $\mathrm{R}=0,63$ ). 0 tipo de desastre que apresenta maior correlação com o IEOI é inundação $(0,52)$, embora não seja o que apresenta maior número de registros (enxurradas).

Com base na Figura 5 e nas Tabelas 3 e 4, pode-se verificar que: a) os municípios com população maior que 60.000 habitantes apresentam maior IEOI; b) os municípios com maior PIB à preços 
correntes apresentam maior IEOI; c) entre as tipologias de desastres, há correlação entre o IEOI e as ocorrências de inundações (e não de enxurradas, que apresentam maior registro); e d) há correlação entre o IEOI e a quantidade de habitantes em situação de risco de inundação.

A maior correlação do IEOI com a tipologia de desastres inundação, ao invés de enxurradas (que possui maior número de registros), pode apresentar relação com o próprio processo da tipologia: sem considerar aqui o processo que traz maiores perdas e danos, a questão temporal que envolve a formação e a duração do processo de inundações é maior que em enxurradas (processos rápidos). Considerando que nossas percepções são formadas pelo acúmulo de experiências ao longo de nossas vidas (Tuan, 2012), podemos fazer associação com o maior duração temporal que envolve as inundações, o maior tempo com que a pessoa se relaciona com o processo de inundação.

Ressalta-se os casos dos municípios de Ituporanga, que com cerca de 25 mil habitantes alcança IEOI médio $(0,602)$, e Indaial, com cerca de 70 mil habitantes tem IEOI muito baixo $(0,486)$, enquanto municípios de porte populacional similar à Ituporanga apresentam IEOIs muito baixos (Balneário Piçarras - 0,414 e Guabiruba - 0,476); os municípios de porte populacional similar à Indaial apresentam IEOI médio e alto (Gaspar - 0,655 e Rio do Sul - 0,764). 0 IEOI médio de Ituporanga pode se relacionar ao fato do município abrigar uma das 3 barragens de contenção de cheias da BHRI, a Barragem Sul; embora nos municípios que abrigam as Barragens Oeste e Norte, não se observa a mesma relação entre população e IEOI (Taió - 0,578, José Boiteux - 0,410 respectivamente). Quanto ao IEOI muito baixo do município de Indaial, também cabe ressaltar que a possibilidade de deflagrar a disponibilização parcial de dados por parte do município, questão à que o levantamento de dados disponibilizado pelos Gestores Municipais de Defesa Civil está exposto.

\section{Análise da Matriz de Resiliência Local}

A resiliência é uma propriedade, uma capacidade e um processo dinâmico pelo qual um sistema é capaz de lidar com interrupções em sua funcionalidade principal, em escalas micro ou macro. As cidades e sociedades, como sistemas dinâmicos que são, estão constantemente incorporando novas informações e novas práticas à sua função e identidade principais em vários níveis (Florini \& Trump, 2018). Essas ideias definem a espinha dorsal de sistemas adaptativos complexos, nos quais os sistemas influenciam e são influenciados por outros sistemas, subsistemas e condições ambientais mais amplas (Florini \& Trump, 2018).

O estudo desenvolvido utiliza dois desses elementos na construção da Matriz de Resiliência Local, apresentada na Figura 6. A Matriz de Resiliência Local analisa a relação entre a população total estimada do município - como o elemento exposição ao risco - e seu desempenho no IEOI - sua capacidade de lidar com riscos de desastres; podendo-se analisar diferentes cenários de resiliência dos municípios.

O estudo utiliza os dados de população estimada para 2020 nos município pois a) apresentam maior relação na Análise de Correlação do item anterior; b) os dados de população exposta à risco de inundação apresentam diferenças de percentuais contrastantes entre os municípios, havendo casos em que os municípios possuem número populacional e de registros de ocorrências de inundações consideráveis, mas a parcela da população exposta é baixa, nula ou os dados não foram apresentados (Tabela 3); e c) a não existência de dados de população exposta para todas as tipologias de desastres. A matriz evidencia quatro cenários:

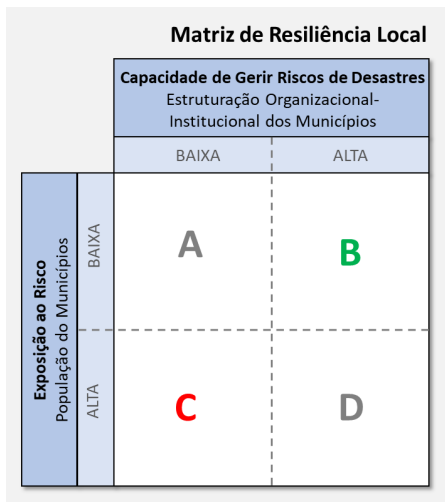

Figura 6 - Matriz de Resiliência Local - análise da relação entre a capacidade de Estruturação OrganizacionalInstitucional para GRD e a população exposta à riscos de desastres em municípios. 
- Cenário A: estabelece uma relação entre uma condição de baixa exposição e uma baixa capacidade de gerir riscos;

- Cenário B (mais resiliente): estabelece uma relação entre uma condição de baixa exposição e de alta capacidade de gerir risco;

- Cenário C (não resiliente): estabelece uma relação entre uma condição de alta exposição e uma baixa capacidade de gerir riscos.

- Cenário D: estabelece uma relação entre uma alta exposição com uma alta capacidade de gerir riscos.

Enquanto os cenários $\mathrm{A}$ e $\mathrm{D}$ apresentam situações relativas de vulnerabilidade à riscos de desastres, os cenários B e C deflagram extremos: o cenário B, mais resiliente, com menor exposição e alto IEOI, e o cenário $C$, não resiliente, com alta exposição e baixo IEOI. 0 cenário C se apresenta como o prioritário à intervenção, por ser o mais vulnerável, seguido simultaneamente pelos cenários A e D. A partir dessa matriz conceitual e cenários de resiliência estabelecidos, sua aplicação à área de estudo permite visualizar os cenários em que estão os municípios da BHRI (Figura 7). Os municípios são apresentados em ordem crescente de número de habitantes (população exposta) e a classificação do IEOI é representada pela cor e dimensionamento da barra que representa cada município. Foram adotados como critério para localizar os eixos de divisão dos cenários: eixo vertical - o limite entre as colunas de IEOI baixo e médio; e eixo horizontal - o limite entre as primeiras classes de tamanho de municípios que possui municípios com IEOI médio. Os resultados da Figura 7 também foram espacializados em mapa da BHRI, na (Figura 8), onde os municípios aparecem com preenchidos na cor relativa ao cenário atribuído à ele.

O eixo horizontal de divisão de cenários da matriz ficou localizado no limite de 20 mil habitantes por município. É a partir de 20 mil habitantes que surge a classificação de IEOI médio, sendo 20 mil habitantes um dos limites estabelecido pela política urbana brasileira para exigência de elaboração do Plano Diretor Físico-Territorial aos municípios. Todos os municípios da BHRI possuem Plano DiretorFísico Territorial.

A aplicação da Matriz de Resiliência Local permite verificar que a maioria dos municípios (35) se classificam como cenário A, com baixa exposição e baixo IEOI. Não existem municípios classificados como cenário B mais resiliente. Cinco municípios - Balneário Piçarras, Guabiruba, Penha, Timbó e Indaial) são classificados como cenário C, não resiliente, com alta exposição e baixo IEOI. Os seis municípios classificados como cenário D - Ituporanga, Gaspar, Rio do Sul, Brusque, Itajaí e Blumenau - apresentam alta exposição e maior IEOI. A aplicação da Matriz de Resiliência Local indica que os cinco municípios do cenário C são prioritários no aumento na capacidade de estruturação organizacional-institucional para gestão de risco de desastres, dada a população exposta.

A espacialização dos municípios segundo os cenários da Matriz de Resiliência Local mostra que os municípios mais vulneráveis (cenário C) estão nas partes média e baixa da Bacia (AMMVI e AMFRI), embora a AMAVI (parte alta da Bacia) tenha obtido menor IEOI. A AMAVI não apresentou municípios classificados no cenário mais vulnerável e é a AM que mais representa o cenário A - baixas exposição e IEOI (25 dos 35 municípios). A AMMVI tem maioria entre os municípios do cenário D - altas exposição e IEOI (quatro dos seis municípios). Os municípios da BHRI com menor IEOI não são os mais vulneráveis à riscos de desastres, pois a vulnerabilidade também está vinculada à exposição. 
Matriz de Resiliência Local - BHRI

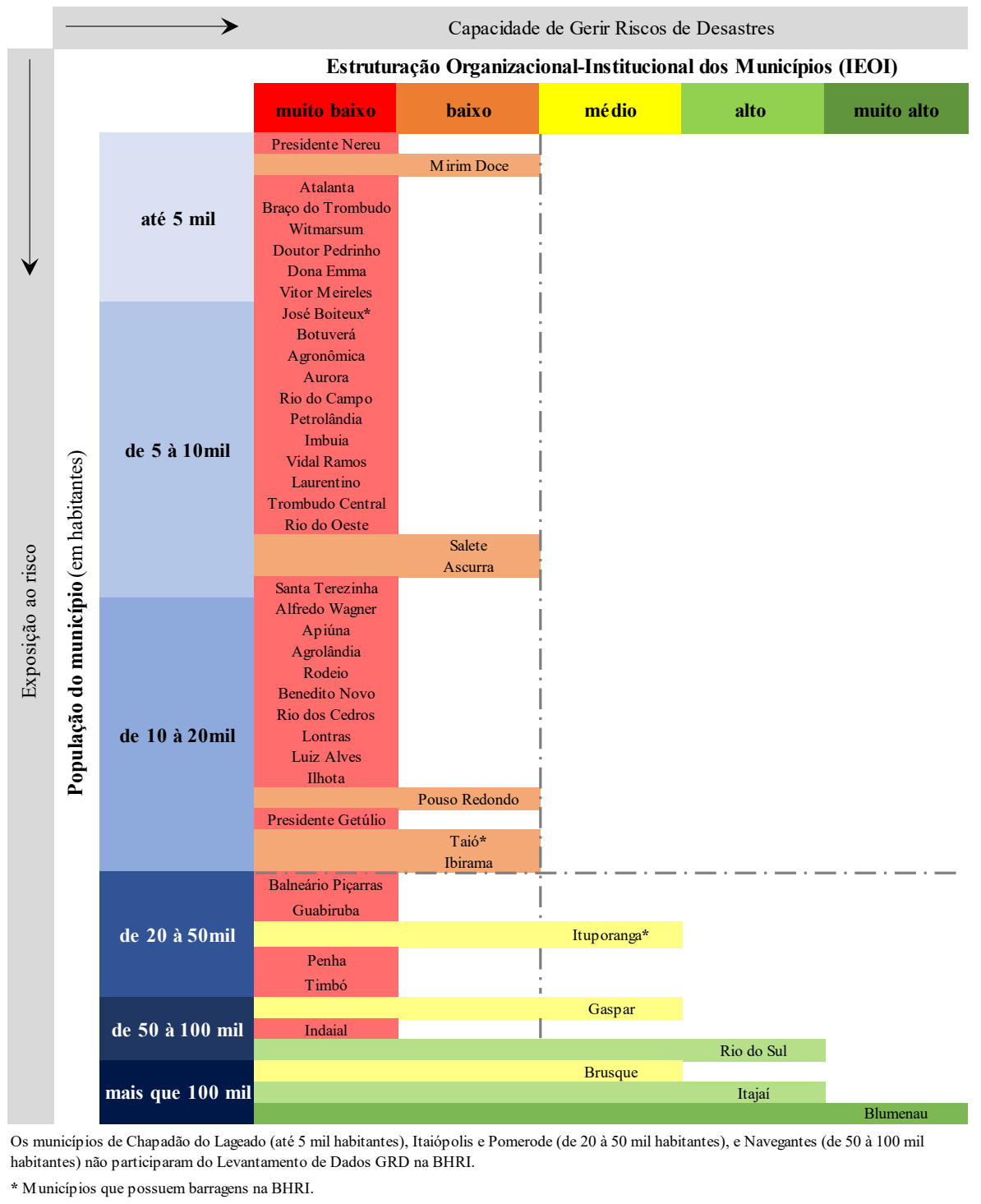

Figura 7 - Matriz de Resiliência Local aplicada aos municípios da bacia hidrográfica do Rio Itajaí.

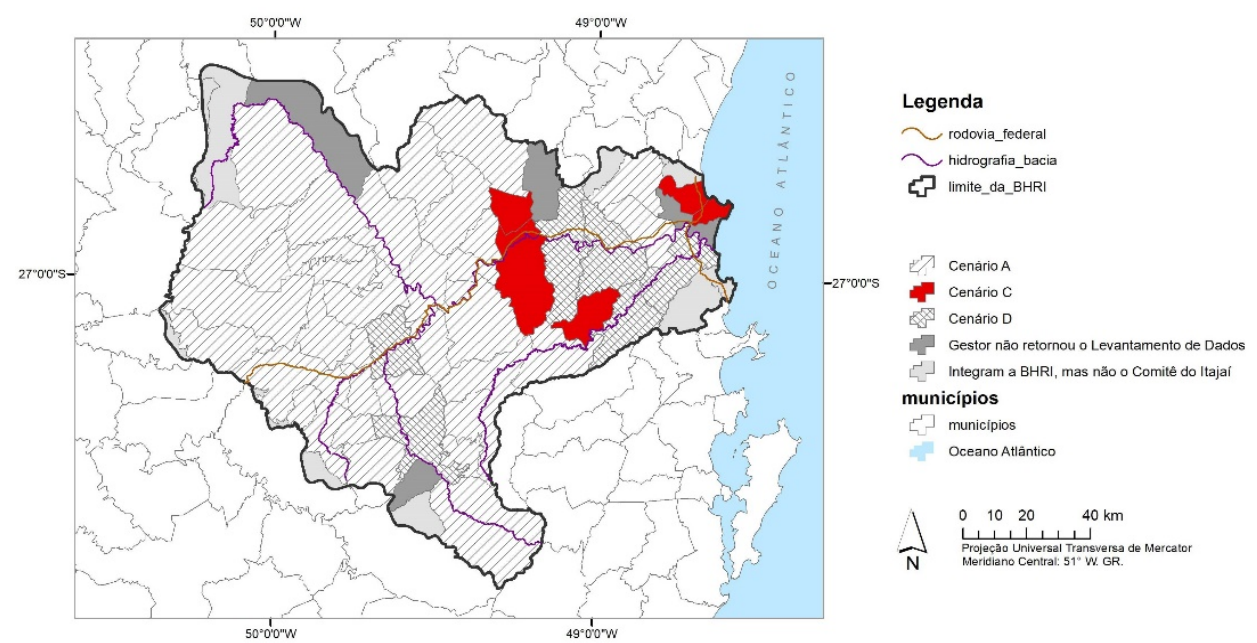

Figura 8 - Espacialização da Matriz de Resiliência Local na bacia hidrográfica do Rio Itajaí. Base: INPE (2015). 


\section{CONSIDERAÇÕES FINAIS}

A análise de cenários da Matriz de Resiliência Local mostra que o padrão de desenvolvimento da BHRI conduziu para vulnerabilização a riscos de desastres, ou seja, a capacidade de estruturação organizacional-institucional para gestão de risco de desastres na Bacia como um todo não acompanhou o agravamento da exposição da população. A baixa estruturação organizacionalinstitucional reflete a baixa tolerância da população à riscos de desastres, sua capacidade de resiliência. $\mathrm{O}$ aumento da vulnerabilidade intensifica o impacto dos riscos de desastres. Apesar de alguns municípios terem fortalecido sua estrutura organizacional-institucional para gestão de risco de desastres e até tornar-se estudo de caso referência, este estudo trouxe evidências contrárias à visão dominante sobre a BHRI. A realidade da região da BHRI é de vulnerabilidade aos riscos de desastres. Compreender a realidade do território é o primeiro passo para geri-lo. Investir no fortalecimento da capacidade de estruturação organizacional-institucional para GRD da sociedade é caminho para diminuir a vulnerabilidade social.

Por meio do estudo de caso, foi possível demonstrar que a metodologia de desenvolvimento do IEOI na BHRI apresenta viabilidade em expressar, de forma simplificada, a complexidade da estruturação organizacional-institucional para a governança e gestão integrada de riscos de desastres em bacias hidrográficas e outras unidades de gestão. O IEOI permite sua análise em nível territorial de município, AMs e de bacia hidrográfica; e análises de cenários de vulnerabilidade local, identificando municípios que requerem ação prioritária para estruturação organizacional-institucional. Os comitês de bacia - "como espaços de governança territorial inquestionável" (Ávila et al., 2020), e as AMs como representações regionais que perduram e dão suporte ao desenvolvimento de diferentes contextos regionais; são atores transversais de grande potencial contributivo à integração das políticas públicas de recursos hídricos e de riscos de desastres. A efetiva integração destas políticas públicas pode contribuir para o fortalecimento da estruturação organizacional-institucional municipal, que pode atuar de forma confluente à gestão de recursos hídricos e de riscos de desastres. Trata-se de uma estratégia integrada de capilarização de políticas públicas.

Mesmo sendo considerada a bacia hidrográfica como unidade de planejamento das políticas nacionais de recursos hídricos e de gestão de risco de desastres hidrometeoriológicos, os municípios devem ter considerado seu protagonismo - enquanto nível territorial local que implementa as políticas públicas como ação e faz a interface entre a população e outras instâncias governamentais na integração da gestão de risco de desastres e da água, necessários para seu desenvolvimento territorial enquanto região.

\section{AGRADECIMENTOS}

À todas as Instituições apoiadoras do Levantamento de Dados GRD na BHRI: a Secretaria Estadual da Defesa Civil de Santa Catarina e suas COREDECs, o Comitê do Itajaí, as Associações de Municípios AMAVI, AMFRI e AMMVI, por meio de seus Coordenadores dos Colegiados de Defesa Civil; e à cada um dos 46 municípios da BHRI que participantes do levantamento, representados pelo Gestor Municipal de Defesa Civil.

Ao Ministério da Integração Nacional (MIN), em especial: a) ao Centro Nacional de Gerenciamento de Riscos e Desastres (CENAD/MIN), na pessoa do Sr. Rafael Pereira Machado - analista de infraestrutura, pela disponibilização de dados do cadastrado de municípios no Sistema Integrado de Informações sobre Desastres (S2ID); e b) à Secretaria Nacional de Proteção e Defesa Civil (SEDEC/MIN), na pessoa do Sr. Marco Aurélio Franco - assistente técnico, pela disponibilização dos dados de repasses financeiros aos municípios por Cartão de Pagamento da Defesa Civil (CPDC).

À instituição mantenedora do programa de pós-graduação, pelo subsídio de bolsa parcial de doutoramento ao autor principal.

\section{REFERÊNCIAS}

Adger, N., Brooks, N., Bentham, G., Agnew, M., \& Eriksen, S. (2004). New indicators of vulnerability and adaptative capacity (Technical Report, No. 7). Norwich: Tyndall Centre for Climate Change Research. Recuperado em 14 de outubro de 2020, de https://nickbrooks.files.wordpress.com/2012/01/tynrepit1_11.pdf

Ávila, H. D. D., Nascimento, J. F., Figueiredo, M. G. B., \& Sampaio, J. B. (2020). A Governança Política no Comitê de Bacia do Rio Paraguaçu. Redes, 25(3), 1164-1184. http://dx.doi.org/10.17058/redes.v25i3.15243

Banco Mundial. (2018). World Bank country and lending groups: country classification. Washington, DC: World Bank. Recuperado em 14 de janeiro de 2018, de 
https://datahelpdesk.worldbank.org/knowledgebase/articles/906519-world-bank-country-and-lendinggroups

Beck, U. (2015). Sociedade de risco mundial: em busca da segurança perdida (448 p.). Lisboa: Edições 70.

Blumenau. Secretaria de Defesa do Cidadão. (2018). Defesa civil. Recuperado em 20 de maio de 2018, de https://www.blumenau.sc.gov.br/governo/secretaria-de-defesa-do-cidadao/pagina/defesa-civil-sedeci

Braga, T., Oliveira, E., \& Givisiez, G. (2006). Avaliação de metodologias de mensuração de risco e vulnerabilidade social a desastres naturais associados à mudança climática. São Paulo em Perspectiva, 20(1), 81-95. Recuperado em 14 de outubro de 2020, de http://www.abep.org.br/publicacoes/index.php/anais/article/view/1615

Brasil. (1997, 9 de janeiro). Lei no 9.433, de 8 de janeiro de 1997. Institui a Política Nacional de Recursos Hídricos. Diário Oficial [da] República Federativa do Brasil, Brasília. Recuperado em 20 de setembro de 2018, de http://www.planalto.gov.br/ccivil_03/Leis/L9433.htm

Brasil. (2012, 11 de abril). Lei no 12.608, de 10 de abril de 2012. Institui a Política Nacional de Proteção e Defesa Civil. Diário Oficial [da] República Federativa do Brasil, Brasília. Recuperado em 3 de janeiro de 2013, de http://www.planalto.gov.br/ccivil_03/_Ato2011-2014/2012/Lei/L12608.htm

Brasil. Ministério da Integração Nacional. Secretaria Nacional de Proteção e Defesa Civil. Departamento de Prevenção e Preparação. (2017). Módulo de formação: noções básicas em proteção e defesa civil e em gestão de riscos: libro base. Brasília: Ministério da Integração Nacional. Recuperado em 5 de junho de 2018, de https://www.undp.org/content/dam/brazil/docs/publicacoes/paz/gestao-risco-livro-base.pdf

Brasil. Ministério do Desenvolvimento Regional. Secretaria de Saneamento. Sistema Nacional de Informações sobre Saneamento. (2019). 3o Diagnóstico de Drenagem e Manejo das Águas Pluviais Urbanas (195 p.). Brasília: SNS/MDR. Recuperado em 5 de junho de 2018, de http://www.snis.gov.br/diagnostico-anualaguas-pluviais/diagnostico-do-servico-de-aguas-pluviais-2018

Comitê do Itajaí. Sistema de Informações de Recursos Hídricos do Estado de Santa Catarina. (2010). Plano de recursos hídricos da bacia do Rio Itajaí: documento síntese. Recuperado em 20 de novembro de 2018, de http://www.sirhesc.sds.sc.gov.br/sirhsc/baixararquivo.jsp?id=527\&NomeArquivo=Plano\%20de $\% 20$ Bacia \%20do\%20Itaja\%ED\%20-\%20Documento\%20S\%EDntese.pdf

Creswel, J. W. (2010). Projeto de pesquisa: métodos qualitativos, quantitativos e mistos. Porto Alegre: Artmed.

Cutter, S. L. (2011). A ciência da vulnerabilidade: modelos, métodos e indicadores. Revista Critica de Ciencias Sociais, 95, 59-69. http://dx.doi.org/10.4000/rccs.165

Das, M. B., \& Majumdar, S. (2019). What does social inclusion mean for a resilient city?: a policy note on urban floods. Washington: World Bank Group. Recuperado em 20 de setembro de 2018, de http://documents.worldbank.org/curated/en/419471557258628314/What-Does-Social-Inclusion-Meanfor-a-Resilient-City-A-Policy-Note-on-Urban-Floods

Djalante, R., \& Lassa, S. (2019). Governing complexities and its implication on the Sendai framework for Disaster Risk Reduction priority 2 on governance. Progress in Disaster Science, 2, 100010.

Dilley, M. R. S., Chen, B., Deichmann, U., Lerner-Lam, A., \& Arnold, M. (2005). Natural disaster hotspots: a global risk analysis. Washington: World Bank Publications. Recuperado em 14 de outubro de 2020, de https://openknowledge.worldbank.org/handle/10986/7376

Dulac, V. F., \& Kobiyama, M. (2017). Interfaces entre políticas relacionadas a estratégias para redução de riscos de desastres: recursos hídricos, proteção e defesa civil e saneamento. Revista de Gestão de Águas da América Latina, 14, 1-20.

Eskelsen, C. R. (2016). Bacia do Rio Itajaí. Recuperado em 16 de fevereiro de 2016, de http://www.365mapas.com.br/mapas/bacia_itajai_3d/index.html

Florini, M.-V., \& Trump, B. D. (2018). Resilience in the context of systemic risks: perspectives from IRGC's guidelines for the governance of systemic risks. In B. D. Trump, M.-V. Florin, \& I. Linkov (Orgs.), IRGC resource guide on resilience (Vol. 2). Lausanne: EPFL. Recuperado em 3 de novembro de 2014, de https://infoscience.epfl.ch/record/262527/files/IRGC\%20Resource\%20guide\%20on\%20resilience\%20\% 28 Volume $\% 202 \% 29$.pdf $\#$ page $=60$

Frank, B., \& Bohn, N. (2018). História da gestão do risco e inundações na bacia do Itajaí. In Desastre de 2008+10 no vale do Itajaí: água, gente e política: aprendizados (pp. 117-150). Blumenau: Edifurb. Recuperado em 3 de março de 2019, de https://desastrefurb.wixsite.com/portal/2008-10-o-que-aprendemos

Frank, B., \& Pinheiro, A. (2003). Enchentes na bacia do Rio Itajaí: 20 anos de experiências (237 p.). Blumenau: Edifurb. 
Freitas, A. S. (2017). Gestão de riscos e desastres: análise da estrutura dos órgãos de proteção e defesa civil do Ceará (Trabalho de conclusão de curso). Faculdade de Economia, Administração, Atuária e Contabilidade, Universidade Federal do Ceará, Fortaleza. Recuperado em 14 de outubro de 2020, de http://www.repositorio.ufc.br/handle/riufc/36952

Garcias, C. M., Ferentz, L. M. S., \& Pinheiro, E. G. (2019). A resiliência como instrumento de análise da gestão municipal de riscos e desastres. Redes, 24(2), 99-121. http://dx.doi.org/10.17058/redes.v24i2.13241

Guha-Sapir, D., \& Santos, I. (2013). The economic impacts of naturais disasters. Oxford: Oxford University Press.

Instituto Brasileiro de Geografia e Estatística - IBGE. (2010). Taxa de crescimento populacional (2000-2010) Recuperado em 20 de agosto de 2019, de https://www.ibge.gov.br/estatisticas/downloadsestatisticas.html

Instituto Brasileiro de Geografia e Estatística - IBGE. Sistema IBGE de Recuperação Automática (SIDRA). (2016). Produto interno bruto dos municípios. Recuperado em 10 de outubro de 2016, de https://sidra.ibge.gov.br/pesquisa/pib-munic/tabelas

Instituto Brasileiro de Geografia e Estatística - IBGE. Diretoria de Pesquisas - DPE. Coordenação de População e Indicadores Sociais - COPIS. (2020). Estimativas da população residente para os municípios e para as

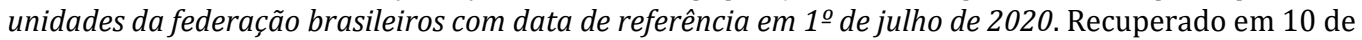
outubro de 2016, de https://www.ibge.gov.br/estatisticas/sociais/populacao/9103-estimativas-depopulacao.html?edicao $=28674 \& \mathrm{t}=$ resultados

Internal Displacement Monitoring Center's - IDMC. (2020). Global report on internal displacement. Geneva: IDMC. Recuperado em 31 de janeiro de 2020, de https://www.internaldisplacement.org/sites/default/files/publications/documents/2020-IDMC-GRID.pdf

Instituto Nacional de Pesquisas Espaciais - INPE. Divisão de Geração de Imagens. (2015). Base cartográfica para representação da bacia hidrográfica do Rio Itajaí. Recuperado em 11 de novembro de 2015, de http://www.dgi.inpe.br/

International Risk Governance Council - IRGC. (2017). Introduction to the IRGC risk governance framework. Lausanne: EPFL International Risk Governance Center. Recuperado em 3 de março de 2019, de https://www.epfl.ch/research/domains/irgc/concepts-and-frameworks/page-139715-en-html/

International Risk Governance Council - IRGC. (2018). Guidelines for the governance of systemic risks. Recuperado em 3 de março de 2019, de https://irgc.org/risk-governance/systemic-risks/guidelinesgovernance-systemic-risks-context-transitions/

Ishiwatari, M. (2019). Flood risk governance: establishing collaborative mechanism for integrated approach. Progress in Disaster Science, 2, 114.

Iwama, A. Y., Batistella, M., Ferreira, L. C., Alves, D. S., \& Ferreira, L. C. (2016). Risco, vulnerabilidade e adaptação às mudanças climáticas: uma abordagem interdisciplinar. Ambiente \& Sociedade, 19(2), 93-116.

Jansen, G. R., \& Vieira, R. (2016). Desastres naturais: o Brasil e a bacia hidrográfica do rio Itajaí/SC. In Atas International Conference on Urban Risks (pp. 251-258). Lisboa, Portugal: Centro Europeu de Riscos Urbanos (CERU). Recuperado em 3 de março de 2019, de http://www.cerueuropa.pt/icur2016/ICUR2016_Proceedings.pdf

Mattedi, M. A., Ludwig, L., \& Avila, M. R. R. (Orgs.) (2018). Desastre de 2008+10 no vale do Itajaí: água, gente e política: aprendizados. Blumenau: Edifurb. Recuperado em 3 de março de 2019, de https://desastrefurb.wixsite.com/portal/2008-10-o-que-aprendemos

Mizutori, M. (2019). From risk to resilience: pathways for sustainable development. Progress in Disaster Science, 2,100011 .

Nações Unidas. (1994). Yokohama strategy and plan of action for a safer world: guidelines for natural disaster prevention, preparedness and mitigation. In World Conference on Natural Disaster Reduction. Yokohama, Japan. Recuperado em 25 de janeiro de 2017, de https://www.undrr.org/publication/yokohama-strategyand-plan-action-safer-world-guidelines-natural-disaster-prevention

Nações Unidas. (2004). Reducing disaster risk: a challange for development, a global report. New York: Programa das Nações Unidas para o Desenvolvimento. Recuperado em 14 de outubro de 2020, de https://www.undp.org/content/undp/en/home/librarypage/crisis-prevention-and-recovery/reducingdisaster-risk--a-challenge-for-development.html

Nações Unidas. Estratégia Internacional para a Redução de Desastres. (2005). Hyogo framework for action 20052015: building the resilience of nations and communities to disasters: extract from the final report of the World Conference on Disaster Reduction (A/CONF.206/6). Geneva: UNISDR. Recuperado em 25 de janeiro de 2017, de https://www.unisdr.org/files/1037_hyogoframeworkforactionenglish.pdf 
Nações Unidas. (2015). Marco de Sendai para la Reducción del Riesgo de Desastres 2015-2030 [Estratégia Internacional para a Redução de Desastres] (versão em português não-oficial - 31 de maio de 2015). UNISDR. Recuperado em 25 de janeiro de 2017, de https://www.unisdr.org/files/43291_spanishsendaiframeworkfordisasterri.pdf

Nações Unidas. (2017). Disaster resilience scorecard for cities [Escritório das Nações Unidas para Redução de Riscos de Desastres]. UNISDR. Recuperado em 14 de outubro de 2018, de https://program.unisdr.org/campaign/resilientcities/toolkit/article/disaster-resilience-scorecard-forcities

Nações Unidas. Escritório das Nações Unidas para Redução de Riscos de Desastres. Centro Belga de Pesquisa sobre Epidemiologia de Desastres - CRED. (2015). The human coast of weather related disaster: 1995-2015. Geneva: CRED, UNDRR. Recuperado em 25 de novembro de 2015, de http://reliefweb.int/sites/reliefweb.int/files/resources/COP21_WeatherDisastersReport_2015_FINAL.pdf

Nações Unidas. Escritório das Nações Unidas para Redução de Riscos de Desastres. United Nations Office for Disaster Risk Reduction - UNISDR. (2015). Marco de Sendai para la Reducción del Riesgo de Desastres 20152030 (Versão em português não-oficial - 31 de maio de 2015). Recuperado em 25 de janeiro de 2017, de https://www.unisdr.org/files/43291_spanishsendaiframeworkfordisasterri.pdf

Nações Unidas. Escritório das Nações Unidas para Redução de Riscos de Desastres. United Nations Office for Disaster Risk Reduction - UNISDR. (2019). Global assessment report: United Nations Office for Disaster Risk Reduction; 2019. Geneva: UNDRR. Recuperado em 3 de março de 2019, de https://gar.unisdr.org/report2019. Acesso em: 10 ago. 2019.

Narváez, L., Lavell, A., \& Ortega, G. P. (2009). La gestión del riesgo de desastres. Secretaría General de la Comunidad Andina. Recuperado em 1 de julho de 2015, de http://www.comunidadandina.org/predecan/doc/libros/PROCESOS_ok.pdf

Nogueira, F. R., Oliveira, V. E., \& Canil, K. (2014). Políticas públicas regionais para gestão de riscos: o processo de implementação no ABC, SP. Ambiente \& Sociedade, 17(4), 177-194.

Ouriques, J. M. A., Sacco, F., \& Bueno, R. L. C. (2018). Defesa Civil de Blumenau: da gestão do desastre para a gestão de riscos de desastres. In Desastre de 2008+10 no vale do Itajaí: água, gente e política: aprendizados (pp. 183-198). Blumenau: Edifurb. Recuperado em 3 de março de 2019, de https://desastrefurb.wixsite.com/portal/2008-10-o-que-aprendemos

PreventionWeb. (2019). Disaster risk reduction \& disaster risk management. Recuperado em 24 de maio de 2020, de https://www.preventionweb.net/risk/drr-drm

Programa das Nações Unidas para o Desenvolvimento - PNUD. (2013). Atlas do Desenvolvimento Humano no Brasil. Recuperado em 18 de fevereiro de 2017, de http://atlasbrasil.org.br/2013/

Santa Catarina. Centro de Informática e Automação do Estado de Santa Catarina. (2016). Base cartográfica interativa de Santa Catarina. Recuperado em 10 de janeiro de 2016, de https://mapainterativo.ciasc.gov.br/

Siebert, C. (2010). Arranjos institucionais e trajetória do planejamento territorial em Santa Catarina. Revista Paranaense de Desenvolvimento, (119), 131-161. Recuperado em 3 de março de 2019, de https://dialnet.unirioja.es/descarga/articulo/4813269.pdf

Tachini, M. (2010). Avaliação de danos associados às inundações no município de Blumenau/SC (Tese de doutorado). Universidade Federal de Santa Catarina.

Tuan, Y.-F. (2012). Topofilia: um estudo da percepção, atitudes e valores do meio ambiente (L. Oliveira, Trad.). São Paulo: Difel.

Universidade Federal de Santa Catarina - UFSC. Centro Universitário de Pesquisa e Estudos sobre Desastres CEPED. (2013). Atlas brasileiro de desastres naturais: 1991 a 20212. Florianópolis: CEPED-UFSC. Recuperado em 15 de outubro de 2018, de https://s2id.mi.gov.br/paginas/atlas/

Wallemacq, P., Below, R., \& McLean, D. (2018). UNISDR and CRED report: economic losses, poverty \& disasters (1998-2017). Recuperado em 14 de fevereiro de 2018, de https://cred.be/unisdr-and-cred-reporteconomic-losses-poverty-disasters-1998-2017

Wisner, B., Baikie, P., Cannon, T., \& Davis, I. (2004). At risk: natural hazards, people's vulnerability and disasters. London: Routledge. 


\section{Contribuições dos autores:}

Giane Roberta Jansen: concepção e execução do projeto. Coleta e tratamento dos dados. Análise e discussão dos resultados. Redação textual e gráfico.

Rafaela Vieira: concepção do projeto. Análise dos resultados.

Marcos Antônio Mattedi: concepção da matriz de resiliência local. Análise e discussão dos resultados

Adilson Pinheiro: análise e discussão dos resultados. Revisão textual. 